\title{
The Good, the Bad, and the Deadly: Adenosinergic Mechanisms Underlying Sudden Unexpected Death in Epilepsy
}

\author{
Benton Purnell', Madhuvika Murugan', Raja Jani' and Detlev Boison ${ }^{1,2,3 *}$ \\ 'Department of Neurosurgery, Robert Wood Johnson Medical School, Rutgers University, Piscataway, NJ, United States, \\ ${ }^{2}$ Rutgers Neurosurgery H.O.P.E. Center, Department of Neurosurgery, Rutgers University, New Brunswick, NJ, \\ United States, ${ }^{3}$ Brain Health Institute, Rutgers University, Piscataway, NJ, United States
}

\section{OPEN ACCESS}

Edited by:

Rui Daniel Prediger,

Federal University of Santa Catarina,

Brazil

Reviewed by:

Robert C. Wykes,

University College London,

United Kingdom

Doo-Sup Choi,

Mayo Clinic College of Medicine and Science, United States

*Correspondence:

Detlev Boison

detlev.boison@rutgers.edu

Specialty section:

This article was submitted to

Neuropharmacology,

a section of the journal

Frontiers in Neuroscience

Received: 11 May 2021

Accepted: 17 June 2021

Published: 12 July 2021

Citation:

Purnell B, Murugan M, Jani R and Boison D (2021) The Good, the Bad, and the Deadly: Adenosinergic Mechanisms Underlying Sudden

Unexpected Death in Epilepsy.

Front. Neurosci. 15:708304. doi: 10.3389/fnins.2021.708304
Adenosine is an inhibitory modulator of neuronal excitability. Neuronal activity results in increased adenosine release, thereby constraining excessive excitation. The exceptionally high neuronal activity of a seizure results in a surge in extracellular adenosine to concentrations many-fold higher than would be observed under normal conditions. In this review, we discuss the multifarious effects of adenosine signaling in the context of epilepsy, with emphasis on sudden unexpected death in epilepsy (SUDEP). We describe and categorize the beneficial, detrimental, and potentially deadly aspects of adenosine signaling. The good or beneficial characteristics of adenosine signaling in the context of seizures include: (1) its direct effect on seizure termination and the prevention of status epilepticus; (2) the vasodilatory effect of adenosine, potentially counteracting postictal vasoconstriction; (3) its neuroprotective effects under hypoxic conditions; and (4) its disease modifying antiepileptogenic effect. The bad or detrimental effects of adenosine signaling include: (1) its capacity to suppress breathing and contribute to peri-ictal respiratory dysfunction; (2) its contribution to postictal generalized EEG suppression (PGES); (3) the prolonged increase in extracellular adenosine following spreading depolarization waves may contribute to postictal neuronal dysfunction; (4) the excitatory effects of $A_{2 A}$ receptor activation is thought to exacerbate seizures in some instances; and (5) its potential contributions to sleep alterations in epilepsy. Finally, the adverse effects of adenosine signaling may potentiate a deadly outcome in the form of SUDEP by suppressing breathing and arousal in the postictal period. Evidence from animal models suggests that excessive postictal adenosine signaling contributes to the pathophysiology of SUDEP. The goal of this review is to discuss the beneficial, harmful, and potentially deadly roles that adenosine plays in the context of epilepsy and to identify crucial gaps in knowledge where further investigation is necessary. By better understanding adenosine dynamics, we may gain insights into the treatment of epilepsy and the prevention of SUDEP.

Keywords: adenosine, epilepsy, SUDEP, status epilepticus, seizure-induced respiratory arrest, adenosine kinase, adenosine receptors, epileptogenesis 


\section{INTRODUCTION}

The purine ribonucleoside adenosine is found ubiquitously in living tissues. In the central nervous system, adenosine is an essential inhibitory modulator of neuronal excitability (Dunwiddie, 1980; Dunwiddie and Masino, 2001; Boison, 2008). Neuronal activity increases adenosine signaling thereby providing negative feedback on excessive excitation (Mitchell et al., 1993; Brager and Thompson, 2003; Pajski and Venton, 2010). The exceptionally high neuronal activity of a seizure results in a surge in extracellular adenosine to concentrations many fold higher than would be observed under normal conditions (During and Spencer, 1992; Berman et al., 2000; Van Gompel et al., 2014). The neuronal inhibition provided by activity-dependent adenosine surging is critical to the prevention and termination of seizures (Dragunow et al., 1985; Murray et al., 1985; Kochanek et al., 2006). Deficits in adenosine signaling can facilitate status epilepticus, a life-threatening event defined by inordinately protracted seizure activity (Young and Dragunow, 1994; Kochanek et al., 2006). In this sense, seizure-induced adenosine surging is highly beneficial. Seizures can also cause periods of profound cerebral hypoxia through postictal vasoconstriction, increased oxygen demand, and respiratory dysfunction (Posner et al., 1969; Farrell et al., 2017; Lacuey et al., 2018). Cerebral hypoxia likely contributes to the pathophysiology of a number of adverse seizure outcomes such as neurodegeneration, memory loss, postictal generalized EEG suppression (PGES), and the postictal state (Seyal et al., 2012; Farrell et al., 2016; LealCampanario et al., 2017; Rheims et al., 2019). Adenosine acts as a cerebral vasodilator and may alleviate the deleterious effects of seizure-induced vasoconstriction (Morii et al., 1986; Arrigoni et al., 2005). Furthermore, adenosine signaling is neuroprotective under hypoxic conditions (Bjorklund et al., 2008; Phillips et al., 2019). As a result, seizure-induced adenosine surging and the increased tissue tone of adenosine are "good" for patient health.

On the other hand, large surges in extracellular adenosine can have detrimental effects. Excessive increases in extracellular adenosine suppress neuronal activity and may contribute to PGES and the postictal state (Rosen and Berman, 1985; During and Spencer, 1992). Though acute seizures cause an increase in extracellular adenosine, chronic epilepsy is associated with a reduction of baseline adenosine levels, which could be a precipitating factor in epileptogenesis (Gouder et al., 2004; Li et al., 2008) and associated co-morbid conditions including cognitive, psychiatric, and sleep disorders (Yee et al., 2007; Boison et al., 2012; Shen et al., 2012; Boison, 2016; Warren et al., 2018). Spreading depolarization waves, which can occur during seizures, result in a prolonged increase in extracellular adenosine

Abbreviations: 5-ITU, 5-iodotubercidin; $\mathrm{A}_{1 / 2 \mathrm{~A}}$, adenosine receptor; $\mathrm{ADK}$, adenosine kinase; ATP, adenosine triphosphate; DPCPX, $\mathrm{A}_{1}$ receptor antagonist; dnSNARE, N-ethylmaleimide-sensitive factor attachment protein receptor; EEG, electroencephalogram; EKG, electrocardiogram; EHNA, erythro-9-(2-hydroxy3-nonyl)-adenine hydrochloride; GEPR-9s, genetically epilepsy-prone rats; $\mathrm{GRAB}_{\text {Ado }}$, GPCR-activation based adenosine sensor; PGES, postictal generalized EEG suppression; SCH 442416, $\mathrm{A}_{2 \mathrm{~A}}$ receptor antagonist; SUDEP, sudden unexpected death in epilepsy.
(Lindquist and Shuttleworth, 2014; Loonen et al., 2019). This increase in adenosine contributes to the neuronal dysfunction that persists in the wake of a spreading depolarization wave (Lindquist and Shuttleworth, 2017). Additionally, under certain circumstances, $\mathrm{A}_{2 \mathrm{~A}}$ receptor activation may have proconvulsant effects (Zeraati et al., 2006; Fukuda et al., 2011); however, anticonvulsant effects of $\mathrm{A}_{2} \mathrm{~A}$ receptor activation have also been described (De Sarro et al., 1999; Huber et al., 2002). Of concern, adenosine suppresses breathing and attenuates the hypercapnic ventilatory response through inhibition of brainstem respiratory sites (Gettys et al., 2013; Falquetto et al., 2018). Seizure-induced increases in brainstem adenosine levels may make seizures more dangerous by preventing an adequate respiratory response to postictal blood gas derangement. For these reasons, seizure-induced adenosine surging is "bad" for patient health.

The adverse effects of seizure-induced adenosine surging may play a critical role in seizure-induced death. The leading cause of epilepsy-related death in patients with refractory epilepsy is sudden unexpected death in epilepsy (SUDEP; Hesdorffer et al., 2011). More years of potential life are lost due to SUDEP than any other neurological condition with the exception of stroke (Thurman et al., 2014). Currently, there are no reliable means of preventing SUDEP or identifying those who are at the highest risk (Massey et al., 2014; Devinsky et al., 2016; Dlouhy et al., 2016). Convergent lines of evidence from epilepsy patients and animal models suggests that SUDEP is the result of some combination of respiratory, cardiac, and electrocerebral dysfunction in the postictal period (Jehi and Najm, 2008; Massey et al., 2014; Aiba and Noebels, 2015; Dlouhy et al., 2016). The precise pathophysiology of SUDEP is the subject of a vibrant ongoing debate (Auerbach et al., 2013; Aiba and Noebels, 2015; Budde et al., 2018; Vega, 2018; Vilella et al., 2019). Currently, the most reliable information on the terminal cascade which precedes SUDEP comes from a case series of SUDEP events occurring in epilepsy monitoring units in which video, electrocardiogram (EKG), and electroencephalogram (EEG) were simultaneously recorded (Ryvlin et al., 2013). In all cases in which breathing and cardiac function could be assessed, terminal apnea preceded terminal asystole indicating that respiratory failure was the primary cause of death (Ryvlin et al., 2013). In the forebrain, seizureinduced adenosine surging has the beneficial effect of stopping seizures; however, excessive adenosine signaling may potentiate SUDEP through respiratory suppression, PGES exacerbation, and attenuation of the hypercapnic ventilatory response (Shen et al., 2010; Ashraf et al., 2020). Experimental evidence from animal models of seizure-induced death suggests that excessive adenosinergic signaling contributes to SUDEP pathophysiology (Shen et al., 2010; Fukuda et al., 2011; Faingold et al., 2016; Kommajosyula et al., 2016). Hence, seizure-induced adenosine surging must be tightly controlled to prevent the potentially disastrous outcomes of status epilepticus and SUDEP. In this review, we summarize the evidence pertinent to the adenosine hypothesis of SUDEP and describe the multifarious effects of adenosine signaling in the context of epilepsy: the good, the bad, and the deadly. 


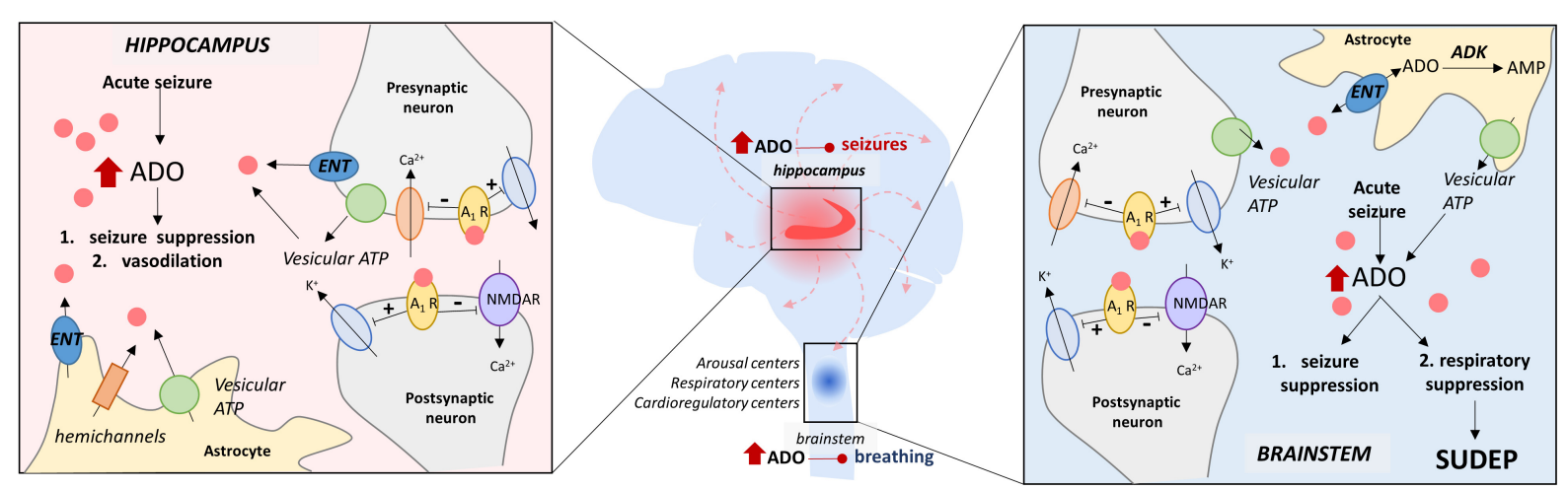

FIGURE 1 | The adenosine hypothesis of SUDEP. This schematic illustrates the hypothesized similarities and differences in periictal adenosine surging and its effects in the hippocampus and the brainstem. In the hippocampus, the ADO surge is important for seizure termination and vasodilation, whereas, in the brainstem, the ADO surge is double-edged and can suppress respiration/breathing in addition to seizure suppression. The key elements of ADO signaling depicted here include (i) vesicular ATP, (ii) equilibrative nucleoside transporters (ENT), (iii) adenosine kinase (ADK), (iv) adenosine receptor ( $\mathrm{A}_{1} \mathrm{R}$ ), and (v) N-methyl D-aspartate receptors (NMDAR).

\section{THE GOOD}

\section{Adenosine and Seizure Cessation}

In the central nervous system, adenosine is released in neural tissue in response to endogenously generated activity (Mitchell et al., 1993; Nguyen and Venton, 2015). Exogenously evoked neuronal activity also triggers an increase in extracellular adenosine (Sulakhe and Phillis, 1975; Lloyd et al., 1993; Pajski and Venton, 2010; Tawfik et al., 2010). The magnitude of the activity-dependent adenosine release increases with the intensity of stimulation (Mitchell et al., 1993; Sciotti et al., 1993; Pajski and Venton, 2010). The high amplitude and high frequency firing of epileptiform discharges results in more neuronal activity than would occur under normal conditions (Merricks et al., 2015). Therefore, it is unsurprising that seizures result in a surge in extracellular adenosine to concentrations much higher than those seen under normal conditions (Figure 1; During and Spencer, 1992; Berman et al., 2000; Aden et al., 2004). Adenosine is an inhibitory modulator of presynaptic neurotransmission and activity dependent adenosine release is critical to keeping neural excitability in check (Dunwiddie and Masino, 2001).

Interestingly, the source of activity-dependent adenosine release remains elusive. There are a number of potential sources of extracellular adenosine (Latini and Pedata, 2001; Wall and Dale, 2008). The mechanism responsible for activity dependent adenosine release varies depending on the brain region (Pajski and Venton, 2013) and the parameters of neural activity (Cunha et al., 1996). Furthermore, activity-dependent adenosine release can occur through several mechanisms simultaneously. A study with transgenic mice with an inducible astrocyteselective mutation of soluble $\mathrm{N}$-ethylmaleimide-sensitive factor attachment protein receptor (dnSNARE-mice) suggests that astrocytic vesicular release of adenosine triphosphate (ATP) is the major source of synaptic adenosine (Pascual et al., 2005). On the other hand, hippocampal neuronal activity results in increased extracellular adenosine via a combination of astrocytic ATP release, and neuronal adenosine release through equilibrative nucleoside transporters (Wall and Dale, 2013). Contrary to this, another study showed that blocking the conversion of ATP to adenosine did not alter the inhibition of neuronal activity associated with high frequency stimulation, suggesting that neuronal adenosine release, and not astrocytic ATP release mediated feedback inhibition of excitatory activity (Lovatt et al., 2012).

Whatever the source of extracellular adenosine, the breakdown is controlled by intracellular astrocytic adenosine kinase (ADK); thus, the tone of ambient adenosine is maintained by an astrocyte-based adenosine-cycle (Fredholm et al., 2005). It is noteworthy, that during chronic epileptic conditions ADK expression is upregulated and consequently the tissue tone of adenosine is drastically reduced (Boison, 2012). Hence, the seizure-induced surge of adenosine combined with a low basal level of adenosine creates a complex reperfusion scenario that needs to be investigated particularly in the context of SUDEP.

Adenosine receptors are G-protein-coupled and exert their effects on neuronal excitability through several transduction pathways. $A_{1}$ receptors, which are coupled to $G_{i / o}$ proteins (Fredholm et al., 2011), hyperpolarize neurons by activating potassium channels (Figure 1; Trussell and Jackson, 1985) and inhibiting voltage dependent calcium channels (Figure 1; MacDonald et al., 1986). On the other hand, $A_{2 A}$ receptors, which are coupled to $G_{s / \text { olf }}$ proteins (Fredholm et al., 2011), are linked to adenylyl cyclase activation and are thought to have an excitatory effect on neurons upon activation (Corvol et al., 2001).

Activity-dependent adenosine release alters seizure dynamics largely via interactions with the $A_{1} R$. Reducing the influence of activity dependent adenosine release via $A_{1} R$ antagonists prolongs seizures in animal models (Dragunow and Goddard, 1984). Likewise, the genetic deletion of the $A_{1} R$ increases vulnerability to status epilepticus and traumatic brain injury (Fedele et al., 2006; Kochanek et al., 2006). Conversely, upregulating adenosinergic tone by inhibiting adenosine reuptake or degradation is protective against seizure activity 
(Dragunow and Goddard, 1984; Gouder et al., 2004). Stem cell derived implants with deficient adenosine metabolism suppressed seizures in rats (Guttinger et al., 2005). Those findings from rodent models are relevant for the human brain as upregulation of adenosine signaling in excised human epileptic tissue attenuated spontaneous and evoked epileptiform activity (Kostopoulos et al., 1989). Conversely, the adenosine receptor antagonist caffeine is used clinically for the purpose of prolonging seizure duration following electroconvulsive therapy, ostensibly improving treatment outcomes (Bozymski et al., 2018). In summary, the inhibitory influence of adenosine is critical to seizure termination (Figure 2 and Table $\mathbf{1}$ ).

\section{Adenosine Is Neuroprotective Under Hypoxic Conditions}

The metabolic demand associated with seizures increases $\mathrm{O}_{2}$ consumption and $\mathrm{CO}_{2}$ production (Posner et al., 1969). Insufficient blood gas exchange due to cerebral vasoconstriction, increased metabolism, and seizure-induced respiratory dysfunction contribute to cerebral hypoxia (Posner et al., 1969; Farrell et al., 2017; Lacuey et al., 2018). Reduction in cerebral $\mathrm{O}_{2}$ to less than half of baseline levels can occur within seconds of seizure termination and can last more than an hour (Farrell et al., 2016). Cerebral hypoxia is associated with PGES and the postictal state (Farrell et al., 2016; Kuo et al., 2016; Rheims et al., 2019). Seizure-induced cerebral hypoxia can also contribute to memory disruption (Farrell et al., 2020).

Convergent lines of evidence indicate that adenosine is neuroprotective under hypoxic conditions (Figure $\mathbf{2}$ and Table 1). Adenosine and $A_{1}$ receptor agonists alleviate hypoxic/ischemic damage in cultured cells (Goldberg et al., 1988; Daval and Nicolas, 1994), in isolated slice preparations (Dux et al., 1992; Mori et al., 1992), and in vivo (Evans et al., 1987; von Lubitz et al., 1988; Von Lubitz et al., 1994). Likewise, non-selective and $A_{1}$ receptor specific adenosine antagonists exacerbate hypoxic/ischemic damage in cultured cells (Daval and Nicolas, 1994; Lynch et al., 1998), in isolated slice preparations (Dux et al., 1992), and in vivo (Von Lubitz et al., 1994). The neuroprotective effect of $\mathrm{A}_{1} \mathrm{R}$ mediated adenosine signaling has also been demonstrated in the retina (Larsen and Osborne, 1996). Furthermore, increasing adenosine signaling by reducing its metabolic clearance through inhibition of adenosine deaminase (Phillis and O'Regan, 1989; Lin and Phillis, 1992) or ADK (Miller et al., 1996; Jiang et al., 1997) protects against hypoxic/ischemic damage. Lastly, increasing adenosine signaling by inhibiting its

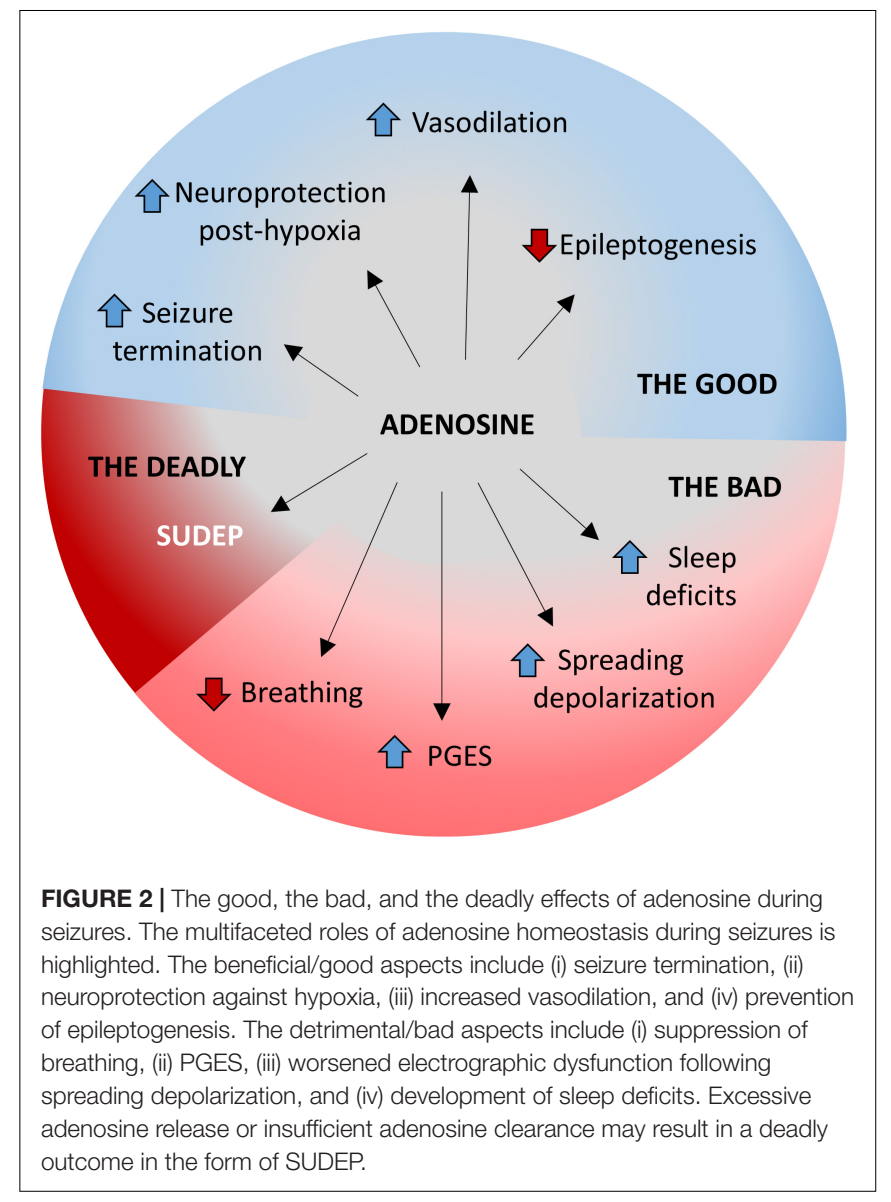

reuptake is neuroprotective under hypoxic/ischemic conditions (DeLeo et al., 1988; Matsumoto et al., 1996).

Though $\mathrm{A}_{1}$ receptor activation is neuroprotective under hypoxic conditions, the opposite appears to be true of the $A_{2 A}$ receptor. $A_{1}$ receptor knockout mice are more vulnerable to hypoxic/ischemic damage (Johansson et al., 2001), whereas the converse is true in $A_{2} \mathrm{~A}$ receptor knockout mice (Chen et al., 1999). A A receptor antagonists alleviate hypoxic/ischemic damage in vivo (Gao and Phillis, 1994; Phillis, 1995; Von Lubitz et al., 1995) and the $\mathrm{A}_{2 \mathrm{~A}}$ receptor antagonist KW-6002 is now FDA approved as an adjunct treatment for Parkinson's disease (Berger et al., 2020; Chen and Cunha, 2020).

TABLE 1 | The beneficial effects of adenosine in the context of seizures and epilepsy.

The Good: Adenosine increases seizure threshold, is critical for seizure termination, and may alleviate some of the adverse effects of seizures.

Seizure cessation

Neuroprotection during hypoxia
The inhibitory influence of adenosine makes seizures less likely and is critical for preventing status epilepticus when seizures do occur.

Convergent lines of evidence indicate that adenosine is neuroprotective under hypoxic conditions such as those observed during seizures.

The vasodilating effect of seizure-induced adenosine surging may attenuate the postictal dysfunction elicited by cerebral vasoconstriction. 
TABLE 2 | The potentially harmful effects of adenosine in the context of seizures and epilepsy.

The Bad: Adenosine surging due to seizures or to secondary depolarization events may adversely affect breathing and EEG activity acutely and sleep chronically.

Respiratory suppression

The postictal state and PGES

Spreading depolarization

Proconvulsant effects

Sleep deficits
Adenosine suppresses breathing and seizure-induced adenosine surging has been implicated in periictal respiratory dysfunction.

Excessive increases in extracellular adenosine suppress neuronal activity and may contribute to PGES and the postictal state.

The increase in extracellular adenosine caused by periictal spreading depolarization may contribute to postictal electrocerebral dysfunction.

Though adenosine is generally inhibitory, there is mixed evidence that under certain circumstances $\mathrm{A}_{2 \mathrm{~A}}$ receptor activation can have proconvulsant effects.

Adenosinergic dysfunction in chronic epilepsy may contribute to comorbid sleep disorders.

\section{Adenosine-Induced Vasodilation}

Cerebral vasoconstriction has been documented in the postictal period in epilepsy patients and in animal models (Newton et al., 1992; Steinhoff et al., 1996; Farrell et al., 2016, 2017). There are several ways in which postictal vasoconstriction might contribute to adverse seizure sequelae. Firstly, vasoconstriction contributes to postictal cerebral hypoxia (Farrell et al., 2016, 2017). As mentioned in the preceding section, postictal cerebral hypoxia has been associated with PGES, the postictal state, and seizure-induced memory impairments (Farrell et al., 2016; Kuo et al., 2016). Secondly, the hypoperfusion caused by repeated seizures may contribute to progressive neurodegeneration (LealCampanario et al., 2017). Fortunately, adenosine is known to act as a vasodilator in the central nervous system (Morii et al., 1986; Arrigoni et al., 2005) and is released in large quantities during seizures (During and Spencer, 1992; Berman et al., 2000; Van Gompel et al., 2014). The vasodilating effect of seizure-induced adenosine surging may attenuate the postictal dysfunction elicited by cerebral vasoconstriction (Figure 2 and Table 1). This hypothesis is supported by the finding that adenosine antagonism worsens the cerebral hypoxia caused by postictal hypoperfusion (Phillips et al., 2019). Taken together, the seizure-induced adenosine surge is beneficial in its effects on seizure termination, prevention of epileptogenesis, vasodilation, and neuroprotection under hypoxic conditions (Figure 2 and Table $\mathbf{1}$ ).

\section{THE BAD}

The inhibitory influence of activity dependent adenosine surging is essential to the regulation of neuronal activity and to the prevention and cessation of seizures (Dragunow et al., 1985; During and Spencer, 1992; Young and Dragunow, 1994; Kochanek et al., 2006); however, excessive adenosine signaling can also have detrimental effects including suppression of breathing, PGES, neuronal dysfunction following spreading depolarization, and may even play a contributing role in the development of comorbid conditions (Figure 2 and Table 2).

\section{Adenosine and Breathing}

Adenosine suppresses breathing by a reduction of both respiratory rate and volume (Figure 2 and Table 2; Eldridge et al., 1984, 1985; Lagercrantz et al., 1984). Interestingly, in mechanically ventilated cats, intracerebroventricular administration of an adenosine analog suppressed respiratory drive while causing the medulla to become acidified (Eldridge et al., 1984), which would normally be expected to increase respiratory drive (Hodges et al., 2004). Because the animals in this study were mechanically ventilated, the medullary acidosis appears to be metabolic in origin and is not explicable by changes in breathing (Eldridge et al., 1984). In adults, adenosine suppresses breathing via its action on the $A_{1}$ receptor (Herlenius et al., 1997; Gettys et al., 2013), but $A_{2 A^{-}}$ mediated suppression of breathing has been documented in neonates (Koos et al., 2001; Mayer et al., 2006). Increases in adenosine signaling in the nucleus tractus solitarius, the pontine reticular formation, and the pre-Bötzinger complex have all been demonstrated to suppress breathing (Douglas et al., 1982; Yan et al., 1995; Gettys et al., 2013).

Respiratory disruption can result in potentially dangerous derangement of blood gasses. The hypercapnic ventilatory response is a life-saving reflex that increases breathing in response to rising $\mathrm{CO}_{2}$ levels (Douglas et al., 1982; Ainslie and Duffin, 2009). In addition to its effect on baseline breathing, adenosine attenuates the hypercapnic ventilatory response (Falquetto et al., 2018). Conversely, adenosine receptor antagonists improve the hypercapnic ventilatory response (Pianosi et al., 1994). Serotonergic neurons in the raphe nuclei are chemosensitive and contribute to the hypercapnic ventilatory response (Hodges et al., 2008; Teran et al., 2014). Serotonin release is inhibited by adenosine agonists and enhanced by adenosine antagonists (Feuerstein et al., 1988; Okada et al., 2001; Arnold et al., 2019). Similarly, the retrotrapezoid nucleus is chemosensitive and may contribute to the hypercapnic ventilatory response (Guyenet et al., 2016). Chemosensitive neurons in the retrotrapezoid nucleus are inhibited by $A_{1}$ receptor activation (James et al., 2018). Increased inhibition of brain areas relevant to respiratory chemoreception, such as the raphe and retrotrapezoid nuclei, may be responsible for the effect of adenosine on the hypercapnic ventilatory response. Sustained hypoxia has a biphasic effect on breathing, initially causing tachypnea but later giving way to bradypnea (Lawson and Long, 1983; Vizek et al., 1987). Rising adenosine levels have been implicated in hypoxia induced hypoventilation (Lopes et al., 1994; Yan et al., 1995), a potential contributor to SUDEP (Tao et al., 2010).

\section{Adenosine and PGES}

Postictal generalized EEG suppression refers to the period of time immediately following a seizure in which the frequency and 
amplitude of EEG activity across the cortex is decreased (Lhatoo et al., 2010; Theeranaew et al., 2018). PGES has been associated with respiratory disturbances, decreased oxygen saturation, and increased postictal immobility (Seyal et al., 2013; Kuo et al., 2016; Rheims et al., 2019). Evidence from animal models indicates that adenosine plays a causal role in PGES (Figure 2 and Table 2). In amygdala kindled rats, systemic pretreatment with an adenosine analog prolongs PGES (Rosen and Berman, 1985; Whitcomb et al., 1990). Pretreatment with the adenosine receptor antagonist caffeine reduces the duration of PGES following amygdala kindled seizures (Whitcomb et al., 1990). Caffeine pretreatment does not alter electrocerebral suppression following electroconvulsive therapy; however, it is not clear whether this would be true in epilepsy patients with spontaneous seizures (Rosenquist et al., 1994). Further evidence is needed to determine whether PGES in epilepsy patients is tractable to adenosinergic manipulation.

\section{Adenosine and Spreading Depolarization}

Spreading depolarization is a slow-moving wave which temporarily silences neuronal activity in the affected tissue (Leo, 1944; Pietrobon and Moskowitz, 2014). Spreading depolarization occurs in a number of diseases but is typically studied in the context of migraines (Lauritzen, 1994; Lauritzen et al., 2011). Seizures have the capacity to generate spreading depolarization waves similar to those seen in migraine patients (Kramer et al., 2017; Ssentongo et al., 2017). Adenosine levels are increased in the wake of spreading depolarization waves (Kaku et al., 1994; Lindquist and Shuttleworth, 2012, 2014; Seidel et al., 2016). The increase in extracellular adenosine brought on by spreading depolarization contributes to the suppression of neuronal activity which persists after the wave of depolarization has passed (Canals et al., 2008; Lindquist and Shuttleworth, 2012, 2017). Unlike in migraines, seizure-induced spreading depolarization can spread to the brainstem (Aiba and Noebels, 2015; Loonen et al., 2019). The propagation of spreading depolarization waves into the brainstem has been implicated as a causal factor in seizure-induced respiratory arrest and death (Aiba and Noebels, 2015; Aiba et al., 2016; Loonen et al., 2019). Whether increases in adenosine associated with seizureinduced spreading depolarization exacerbate postictal neuronal dysfunction or contribute to seizure-induced respiratory arrest has not been empirically investigated (Figure 2 and Table 2).

\section{Potential Proconvulsant Effects of $A_{2 A}$ Receptor Activation}

Though increases in extracellular adenosine are generally anticonvulsant through $\mathrm{A}_{1}$ receptor activation, there are some findings that suggest that under certain circumstances $A_{2} \mathrm{~A}$ receptor activation can be proconvulsant, but evidence for this is mixed. Hippocampal microinjection of an $\mathrm{A}_{2 \mathrm{~A}}$ receptor agonist increased afterdischarge duration following piriform cortex kindled seizures in rats (Zeraati et al., 2006; Hosseinmardi et al., 2007); however, in this same model, microinjection of an $\mathrm{A}_{2 \mathrm{~A}}$ receptor antagonist did not decrease afterdischarge duration (Zeraati et al., 2006; Hosseinmardi et al., 2007). The use of caffeine, a non-selective adenosine receptor blocker, reveals a more nuanced balance between the proconvulsant effect of $\mathrm{A}_{2 \mathrm{~A}}$ receptor activation and the opposing effects of A1 receptor activation (Fredholm et al., 1999; El Yacoubi et al., 2008). Indeed, chronic caffeine administration decreased the susceptibility to chemoconvulsants in mice, an effect that involved $\mathrm{A}_{2 \mathrm{~A}}$ receptor blockade (El Yacoubi et al., 2008). The neuroprotection from preventing $\mathrm{A}_{2 \mathrm{~A}}$ receptor activation was further confirmed using transgenic mice lacking $\mathrm{A}_{2 \mathrm{~A}}$ receptors, which were more resistant to pentylenetetrazol-induced seizures (El Yacoubi et al., 2008).

In a hyperthermia model of seizure induction, the threshold for seizure development in young rats was decreased by pretreatment with an $\mathrm{A}_{2 \mathrm{~A}}$ receptor agonist and increased by $\mathrm{A}_{2 \mathrm{~A}}$ receptor antagonist pretreatment (Fukuda et al., 2011). These findings indicate a proconvulsant effect of $\mathrm{A}_{2 \mathrm{~A}}$ receptor activation; however, data collected in audiogenic seizure models indicated a primarily anticonvulsant effect of $\mathrm{A}_{2 \mathrm{~A}}$ receptor activation (De Sarro et al., 1999; Huber et al., 2002). In contrast, other studies did not find any effects of $\mathrm{A}_{2 \mathrm{~A}}$ receptor activation on seizure activity (Young and Dragunow, 1994; Rezvani et al., 2007; Uzbay et al., 2007; Hargus et al., 2012; Akula and Kulkarni, 2014). Additional evidence is necessary to clarify the conditions under which the $\mathrm{A}_{2 \mathrm{~A}}$ receptor has proconvulsant effects and whether these effects are significant to SUDEP (Figure 2 and Table 2).

\section{Sleep Deficits}

Epilepsy and sleep are interconnected, with one affecting the other (Kotagal and Yardi, 2008; Lanigar and Bandyopadhyay, 2017). Poor sleep is known to act as a trigger for certain forms of epilepsy such as nocturnal frontal lobe epilepsy, benign epilepsy with centrotemporal spikes, and Panayiotopoulos syndrome. On the other hand, having epilepsy can contribute to sleep disturbances and disorders such as insomnia and obstructive sleep apnea (Bazil, 2003; Staniszewska et al., 2017). In this section, we highlight the role of acute seizure-induced surges in adenosine in sleep/wake regulation (Bjorness and Greene, 2009). High adenosine levels promote sleep by inhibiting cholinergic neurons in the basal forebrain (Porkka-Heiskanen et al., 1997). Consistent with this notion, manipulation of ADK affected sleep regulation in mice (Palchykova et al., 2010). Using Kv1.1 knockout mice, a model of temporal lobe epilepsy with comorbid sleep disorders, Warren et al. (2018) demonstrated that surges in adenosine in the dorsal hippocampus and lateral hypothalamus contributed to lower seizure threshold and chronic partial sleep deprivation, respectively. Taken together, these studies suggest that adenosine dysregulation in chronic epilepsy may be responsible for the sleep disruption and sleeprelated co-morbidities observed in epilepsy patients (Figure 2 and Table 2; Boison and Aronica, 2015). It is interesting to note that there is a strong association of SUDEP with sleep, with $\sim 70 \%$ of SUDEP-related deaths occurring during sleep (Ryvlin et al., 2013; Ali et al., 2017). Hence, investigating the relationship between sleep, adenosine, and epilepsy, particularly in the context of SUDEP, may yield significant insights into the pathophysiology of SUDEP. 


\section{THE DEADLY}

\section{The Adenosine Hypothesis of SUDEP}

In 2010, it was observed in a kainic acid rodent seizure model that upregulating adenosine tone by inhibiting its metabolism had the seemingly paradoxical effect of initially preventing seizure activity, but then causing death when a seizure did occur (Shen et al., 2010). To explain this counterintuitive finding and, hopefully, to gain insights into the pathophysiology of SUDEP the adenosine hypothesis of SUDEP was formulated. The adenosine hypothesis of SUDEP suggests that seizure-induced increases in extracellular adenosine result in excessive inhibition of brain areas that are necessary for breathing which precipitates terminal respiratory arrest (Figure 1 and Table 3; Shen et al., 2010). This adenosine based explanation of SUDEP causally links the well-known increase in adenosine during and after seizures to respiratory failure.

The adenosine hypothesis of SUDEP has significant explanatory power regarding the timing of respiratory arrest seen in SUDEP cases. As mentioned in the introduction, the best data currently available on the sequence of events which trigger SUDEP comes from a case series of SUDEP occurring in epilepsy monitoring units (Ryvlin et al., 2013). A consistent, but perplexing observation in these instances of SUDEP is that terminal respiratory failure began in the postictal period. In other words, the seizure ended, the patient was breathing for a period of 1-10 $\mathrm{min}$, then the patient stopped breathing (Ryvlin et al., 2013). In this investigation, breathing was assessed by chest excursions observed by video along with the EEG artifacts associated with breathing (Ryvlin et al., 2013). This is not the most reliable method of respiratory measurement, particularly in situations where the view of the camera might be obstructed with bedding. Furthermore, quantification of tidal volume is not possible using video and EEG artifacts leaving open the possibility of severe hypoventilation prior to the terminal apnea. Nevertheless, the fact remains that the patients were breathing in the postictal period prior to the onset of fatal respiratory arrest (Ryvlin et al., 2013). This observation raises the following question: why do terminal apneas that are caused by seizures emerge when the seizure is over instead of during the seizure or at the end of the seizure? One possible clue that might be useful in answering this question is that the peak of seizure-induced adenosine surging occurs during the postictal period, not during the seizure itself (Van Gompel et al., 2014). If rising adenosine levels were responsible for the seizure-induced respiratory arrest seen in SUDEP one would expect terminal apnea to appear during the postictal period, when adenosine levels are at their highest. This prediction is borne out by clinical observations of SUDEP (Ryvlin et al., 2013).

\section{Evidence Concerning the Role of Adenosine in SUDEP}

In a kainic acid mouse seizure model, the effects of impaired adenosine clearance were investigated by inhibition of the enzymes responsible for adenosine degradation, adenosine deaminase and ADK (Shen et al., 2010). Mice were pretreated with the adenosine deaminase inhibitor erythro-9-(2-hydroxy-3nonyl)-adenine hydrochloride (EHNA) and the ADK inhibitor 5-iodotubercidin (5-ITU) prior to seizure induction via kainic acid. All mice with pharmacologically impaired adenosine clearance underwent seizure-induced death, whereas there was no mortality in the animals that received a saline injection prior to seizure induction. To ascertain whether the observed mortality was due to excessive adenosine signaling, the adenosine receptor antagonist caffeine was administered after the onset of seizure activity in animals treated with kainic acid and inhibitors of adenosine clearance. It was observed that caffeine treatment delayed death, supporting the hypothesis that excessive adenosine surging may play a causal role in the seizureinduced death phenotype (Shen et al., 2010). A limitation of this investigation is the lack of respiratory, cardiac, and electrocerebral quantification which preclude any conclusions regarding the cause of death.

In a more recent study, a similar approach of pharmacological suppression of metabolic adenosine clearance prior to kainic acid seizure induction was taken in rats (Ashraf et al., 2020); however, in this investigation concomitant measurements of EEG, heart rate, blood pressure, and phrenic nerve activity were made to clarify the cause of death. Furthermore, the rats in this study were tracheostomized prior to seizure-induction to rule out the possibility of laryngospasm. Seizure-induced laryngospasm is difficult to differentiate from seizure-induced central apnea and has been hypothesized to contribute to SUDEP pathophysiology (Nakase et al., 2016; Stewart et al., 2017; Budde et al., 2018; Irizarry et al., 2020). Seizure-induced death was observed in animals treated with 5-ITU and kainic acid, but not in animals treated with 5-ITU or kainic acid alone. Suppression of phrenic nerve activity preceded EEG flattening, cardiovascular failure, and death indicating a primarily respiratory cause of death. Unexpectedly, 5-ITU and kainic acid administration resulted in abnormal partial phrenic nerve bursts. These partial bursts were reduced by treatment with caffeine suggesting that they were related to excessive adenosine signaling. The precise cause of these partial phrenic nerve bursts and whether they occur in other seizure models has yet to be determined (Ashraf et al., 2020).

Audiogenic seizures in DBA/2 mice are a frequently used and well characterized model of seizure-induced death (Tupal and Faingold, 2006; Faingold et al., 2011; Irizarry et al., 2020). When subjected to a high intensity broadband acoustic stimulus, susceptible DBA/2 mice experience seizures that can evolve into seizure-induced respiratory arrest and death. Inhibition of adenosine metabolism by 5-ITU pretreatment was associated with an increased incidence of seizure-induced respiratory arrest. Conversely, caffeine pretreatment reduced the incidence of seizure-induced respiratory arrest. These findings indicate that excessive adenosine signaling may contribute to seizure-induced death in this model. Pretreatment with SCH 442416, an $\mathrm{A}_{2 \mathrm{~A}}$ receptor antagonist, reduced the incidence of seizure-induced death. On the other hand, the $A_{1}$ receptor antagonist DPCPX did not alter the probability of seizure-induced death suggesting that excessive $A_{2 A}$ receptor activation is the driving force in the effect of adenosine on vulnerability to seizure-induced death (Faingold et al., 2016). 
TABLE 3 | Experimental evidence which directly supports the adenosine hypothesis of SUDEP.

The Deadly: Seizure-induced increases in extracellular adenosine may precipitate SUDEP by excessive inhibition of brain areas that are necessary for breathing.

\begin{tabular}{|c|c|c|}
\hline Reference & Seizure model & Core findings \\
\hline Shen et al., 2010 & Kainic acid in unanesthetized mice & $\begin{array}{l}\text { Increasing adenosinergic tone by inhibiting adenosine metabolism initially prevented seizure } \\
\text { activity, but later precipitated seizure-induced death. This mortality was delayed by an } \\
\text { adenosine receptor antagonist. }\end{array}$ \\
\hline Ashraf et al., 2020 & $\begin{array}{l}\text { Kainic acid in anesthetized and } \\
\text { tracheostomized rats }\end{array}$ & $\begin{array}{l}\text { Seizure-induced death was only observed in rats with inhibited adenosine metabolism. } \\
\text { Death was the result of central respiratory arrest as opposed to cardiac failure or } \\
\text { laryngospasm. Impaired adenosine metabolism during seizures resulted in abnormal partial } \\
\text { phrenic nerve bursts which were reduced by treatment with an adenosine receptor } \\
\text { antagonist. }\end{array}$ \\
\hline Faingold et al., 2016 & DBA/2 audiogenic seizures & $\begin{array}{l}\text { Pharmacological inhibition of adenosine metabolism increased the likelihood of } \\
\text { seizure-induced death. Non-selective and } A_{2 A} \text { specific adenosine receptor antagonism } \\
\text { decreased the likelihood of seizure-induced death. }\end{array}$ \\
\hline Kommajosyula et al., 2016 & GEPR-9 audiogenic seizures & $\begin{array}{l}\text { Inhibition of adenosine metabolism prolonged postictal motor impairment, exacerbated } \\
\text { respiratory dysfunction, and increased the probability of death. }\end{array}$ \\
\hline
\end{tabular}

Like DBA/2 mice, genetically epilepsy-prone rats (GEPR-9s) experience seizures and seizure-induced respiratory disruption following exposure to a high intensity broadband acoustic stimulus (Faingold, 1988). Seizures in GEPR-9s result in a period of postictal immobility, as indicated by a loss of the righting reflex, and respiratory disruption (Jobe et al., 1995; Kommajosyula et al., 2016). Seizures in GEPR-9s sometimes result in death; however, unlike the DBA/2 mouse, death is uncommon and does not immediately occur after the seizure (Kommajosyula et al., 2016). In this model, pharmacological inhibition of adenosine clearance by co-administration of EHNA and 5-ITU prolonged postictal motor impairment, exacerbated respiratory dysfunction, and increased the probability of death (Kommajosyula et al., 2016).

\section{DISCUSSION}

In summary, the influence of adenosine signaling in the context of epilepsy is nuanced and cannot be indiscriminately categorized as either beneficial or harmful (Figure 2 and Tables 1-3). Insufficient adenosine signaling results in inadequate neuronal inhibition, increased vulnerability to seizures, and the potentially fatal outcome of status epilepticus (Dragunow et al., 1985; Murray et al., 1985; Kochanek et al., 2006); however, paradoxically, excessive adenosine signaling may worsen periictal breathing, exacerbate PGES, and potentiate SUDEP (Rosen and Berman, 1985; Shen et al., 2010; Faingold et al., 2016; Kommajosyula et al., 2016). Though our understanding of the role of adenosine in epilepsy is rapidly improving there are still many unresolved questions and weaknesses in the existing literature that impede the development of adenosine-based therapeutic strategies to prevent SUDEP.

The adenosine hypothesis of SUDEP is largely predicated on the assumption that seizure-induced adenosine surging occurs in the brainstem, where adenosine is known to suppress breathing (Figure 1; Douglas et al., 1982; Yan et al., 1995; Gettys et al., 2013). Seizure-induced adenosine surging has primarily been studied in the context of seizure termination as opposed to seizure-induced death. As a result, seizure-induced adenosine surging has been identified in the hippocampus (Figure 1; During and Spencer, 1992; Berman et al., 2000; Aden et al., 2004; Etherington et al., 2009) and the cortex (Schrader et al., 1980; Van Gompel et al., 2014), but never directly measured in the brainstem. Characterizing the peri-ictal changes in adenosine levels in brainstem respiratory nuclei and nuclei previously implicated in SUDEP pathophysiology will be crucial to validating the adenosine hypothesis of SUDEP (Figure 1).

As discussed in the main body of this review, there are a number of mechanisms responsible for activity-dependent adenosine release. The relative contributions of these mechanisms appear to be regionally dependent. The mechanisms of activity dependent changes in adenosine signaling have primarily been studied using spontaneously occurring or electrically evoked neuronal activity. Insights gained regarding the mechanisms of activity dependent adenosine release in the context of evoked or naturally occurring neural activity may, or may not, be generalizable to seizures. Future investigations should examine the mechanisms underlying seizure-induced adenosine release and elucidate the spread of adenosine wave to the brainstem. Spreading depolarization waves result in an increase in extracellular adenosine which prolongs neuronal dysfunction (Canals et al., 2008; Lindquist and Shuttleworth, 2012, 2017); however, whether seizure-induced spreading depolarization waves elevate extracellular adenosine levels or whether such and increase might contribute to SUDEP is unknown.

Anatomically, where adenosine acts to potentiate SUDEP is unknown. Adenosine suppresses breathing in a variety of brainstem sites (Douglas et al., 1982; Yan et al., 1995; Gettys et al., 2013); however, direct evidence on seizureinduced alteration in adenosine levels in these brain areas is lacking. Deficits in serotonergic neurotransmission have been consistently implicated in SUDEP pathophysiology (Richerson and Buchanan, 2011; Faingold et al., 2014; Massey et al., 2014; Zhan et al., 2016; Petrucci et al., 2019). The mechanisms responsible for periictal suppression of serotonergic activity are unknown. The inhibition of serotonin neurons during and after 
seizures may be the result of adenosine surging; however, this has not been empirically investigated.

In addition to the inhibitory effect of adenosine on serotonergic neurotransmission, which is discussed in more detail in the "Adenosine and breathing" subsection, adenosine modulates the signaling of a number of other neurotransmitter systems which are relevant to epilepsy and seizure-induced death. Presynaptic $A_{1}$ receptor activation inhibits the synaptic release of glutamate in brain areas notable for seizure activity, such as the hippocampus (Burke and Nadler, 1988). In contrast, $\mathrm{A}_{2 \mathrm{~A}}$ receptor activation facilitates hippocampal and striatal glutamate release ostensibly by diminishing the inhibitory influence of $\mathrm{A}_{1}$ receptor activation (Popoli et al., 1995; Lopes et al., 2002). Correspondingly, $A_{1}$ receptor antagonism increases glutamate release (Di Iorio et al., 1996; Quarta et al., 2004), whereas $A_{2 A}$ receptor antagonism decreases it (Popoli et al., 2003; Quarta et al., 2004).

Similar to glutamate, GABA release is decreased by $A_{1}$ receptor activation and increased by $\mathrm{A}_{2 \mathrm{~A}}$ receptor activation (Jeong et al., 2003; Hong et al., 2005; Yum et al., 2008). A A receptor mediated excitation of GABA releasing neurons in the respiratory brainstem has been used to explain the observation that both $A_{1}$ and $A_{2 A}$ receptor agonists suppress breathing, despite their divergent effects on neuronal excitability (Wilson et al., 2004; Mayer et al., 2006).

Like serotonin, the monoaminergic transmitter norepinephrine may be protective against seizure-induced death. The norepinephrine reuptake inhibitor, atomoxetine, reduces the likelihood of seizure-induced death following maximal electroshock and audiogenic seizures (Zhang et al., 2017; Zhao et al., 2017; Kruse et al., 2019). Adenosine suppresses neuronal activity in the locus coeruleus (Shefner and Chiu, 1986) and focally inhibits norepinephrine release in the cortex (Harms et al., 1978; Taylor and Stone, 1980). Whether adenosinergic inhibition of norepinephrine neurons alters vulnerability to seizure-induced death has yet to be empirically investigated.

Arousal promoting cholinergic structures in the basal forebrain and brainstem are inhibited by adenosine (Rainnie et al., 1994; Porkka-Heiskanen et al., 1997; Peng et al., 2020). Seizures suppress the activity of cholinergic neurons in the basal forebrain and pedunculopontine tegmental nucleus (Motelow et al., 2015). Given the hypothesized role of the ascending arousal system in the prevention of SUDEP (Massey et al., 2014), the role of adenosinergic inhibition of the cholinergic system during seizures should be investigated.

Most of the experimentation pertinent to the role of adenosine in seizure-induced death has been conducted in acute seizure models, often in seizure-naïve animals. Epileptogenesis and the occurrence of repeated seizures alters the brain in ways that might be meaningful to SUDEP; for instance, an altered expression/function of ADK and adenosine receptors has been noted during epileptogenesis (Patodia et al., 2020). Therefore, it would be beneficial to use models of epilepsy which feature spontaneous seizures and spontaneous seizure-induced death for investigating SUDEP. To this end, Kcna1 ${ }^{-/-}$mice, which lack voltage-gated Kv1.1 channels, experience spontaneous seizures and undergo seizure-induced death at approximately postnatal day 50 (Moore et al., 2014). Dravet syndrome is a severe infantile onset epilepsy with a high rate of SUDEP (Dravet, 1978; Genton et al., 2011). Dravet syndrome is the result of mutations in the Scnla gene which encodes the voltage-gated sodium channel Nav1.1. Mice with similar mutations display phenotypes comparable to those seen in Dravet syndrome, including seizureinduced death which might prove to be an effective tool for SUDEP investigations (Ito et al., 2013; Kalume et al., 2013; Kim et al., 2018).

A growing body of evidence implicates adenosine signaling in a variety of adverse seizure outcomes such as respiratory suppression, PGES, and SUDEP (Figure 2 and Tables 2, 3); however, it is not yet clear how this information can be leveraged to inform clinical preventative strategies. Systemic adenosine receptor antagonism may reduce vulnerability to SUDEP, but there are a number of reasons why this might not be a viable clinical option. Most cases of SUDEP occur during the night, presumably while the patient is asleep (Lamberts et al., 2012; Ali et al., 2017; Purnell et al., 2018). An adenosine antagonist, such as caffeine, taken before bed would be likely to disrupt the patients sleep (Drake et al., 2013). Sleep disruption can result in a variety of adverse health outcomes including an increased likelihood of seizures (Bennett, 1963; Mendez and Radtke, 2001; Medic et al., 2017). Because it is generally agreed that SUDEP occurs consequent to a seizure (Ryvlin et al., 2013; Massey et al., 2014), anything that might impair a patients seizure control should be avoided. Furthermore, adenosine receptor antagonists can prolong seizures potentially increasing the amplitude of the seizure-induced adenosine surge (Dragunow and Goddard, 1984; Bozymski et al., 2018). The beneficial effect of antagonizing adenosine receptors might be counteracted by a higher surge in extracellular adenosine following seizure termination. Lastly, chronic administration of adenosine receptor antagonists can result in increased adenosine receptor expression (Fredholm, 1982). An increase in adenosine receptor expression, particularly in the brainstem, might increase vulnerability to seizure-induced respiratory arrest.

Sudden unexpected death in epilepsy typically occurs during sleep (Ali et al., 2017). Given the role of changing adenosine concentrations in sleep/wake regulation (Basheer et al., 2004) and the adenosine hypothesis of SUDEP outlined in this review, the reader may arrive at the conclusion that differential adenosine concentrations during sleep might be in some way related to the increased incidence of SUDEP during sleep. It should be noted that the increase in adenosine over the course of wakefulness is primarily localized to the basal forebrain and is absent in the dorsal raphe, an arousal promoting brainstem nucleus which has been implicated in SUDEP (PorkkaHeiskanen et al., 2000; Zhang et al., 2018; Petrucci et al., 2020). Furthermore, extracellular adenosine concentrations quickly fall during sleep to levels lower than those seen during wakefulness (Porkka-Heiskanen et al., 1997). Thus, it is not clear whether fluctuations in adenosine are related to the increased rate of SUDEP during sleep.

By improving our understanding of periictal adenosine dynamics and developing novel strategies for influencing adenosinergic signaling we may gain insights into 
how seizures and their most tragic sequelae can be prevented. Therapeutically, adenosine augmentation strategies are some of the most effective strategies for seizure control (Gouder et al., 2003; Boison, 2012), however, SUDEP risk needs to be considered and local adenosine augmentation strategies might be the most effective (Figure 1; Boison, 2009). In addition to the benefits noted here, adenosine augmentation might also help improve affective, psychiatric, and cognitive impairments (Boison and Aronica, 2015); co-morbidities that are prevalent among patients with epilepsy (Gaitatzis et al., 2004; LaFrance et al., 2008). Most importantly, novel findings show that adenosine therapy can prevent epilepsy development through an epigenetic mechanism (Williams-Karnesky et al., 2013; Lusardi et al., 2015; Sandau et al., 2019). Those strategies employed only transiently in a pre-epileptic brain are not expected to be associated with increased SUDEP risk, rather it is intended to

\section{REFERENCES}

Aden, U., O'Connor, W. T., and Berman, R. F. (2004). Changes in purine levels and adenosine receptors in kindled seizures in the rat. Neuroreport 15, 1585-1589. doi: 10.1097/01.wnr.0000133227.94662.c9

Aiba, I., and Noebels, J. L. (2015). Spreading depolarization in the brainstem mediates sudden cardiorespiratory arrest in mouse SUDEP models. Sci. Transl. Med. 7:282ra246.

Aiba, I., Wehrens, X. H., and Noebels, J. L. (2016). Leaky RyR2 channels unleash a brainstem spreading depolarization mechanism of sudden cardiac death. Proc. Natl. Acad. Sci. U.S.A. 113, E4895-E4903.

Ainslie, P. N., and Duffin, J. (2009). Integration of cerebrovascular CO2 reactivity and chemoreflex control of breathing: mechanisms of regulation, measurement, and interpretation. Am. J. Physiol. Regul. Integr. Comp. Physiol. 296, R1473R1495.

Akula, K. K., and Kulkarni, S. K. (2014). Effect of curcumin against pentylenetetrazol-induced seizure threshold in mice: possible involvement of adenosine A1 receptors. Phytother. Res. 28, 714-721. doi: 10.1002/ptr.5048

Ali, A., Wu, S., Issa, N. P., Rose, S., Towle, V. L., Warnke, P., et al. (2017). Association of sleep with sudden unexpected death in epilepsy. Epilepsy Behav. 76, 1-6. doi: 10.1016/j.yebeh.2017.08.021

Arnold, M. R., Williams, P. H., McArthur, J. A., Archuleta, A. R., O’Neill, C. E., Hassell, J. E. Jr., et al. (2019). Effects of chronic caffeine exposure during adolescence and subsequent acute caffeine challenge during adulthood on rat brain serotonergic systems. Neuropharmacology 148, 257-271. doi: 10.1016/j. neuropharm.2018.12.019

Arrigoni, E., Crocker, A. J., Saper, C. B., Greene, R. W., and Scammell, T. E. (2005). Deletion of presynaptic adenosine A1 receptors impairs the recovery of synaptic transmission after hypoxia. Neuroscience 132, 575-580. doi: 10.1016/j. neuroscience.2004.12.009

Ashraf, O., Huynh, T., Purnell, B. S., Murugan, M., Fedele, D. E., Chitravanshi, V., et al. (2020). Suppression of phrenic nerve activity as a potential predictor of imminent sudden unexpected death in epilepsy (SUDEP). Neuropharmacology 184:108405. doi: 10.1016/j.neuropharm.2020.108405

Auerbach, D. S., Jones, J., Clawson, B. C., Offord, J., Lenk, G. M., Ogiwara, I., et al. (2013). Altered cardiac electrophysiology and SUDEP in a model of Dravet syndrome. PLoS One 8:e77843. doi: 10.1371/journal.pone.0077843

Basheer, R., Strecker, R. E., Thakkar, M. M., and McCarley, R. W. (2004). Adenosine and sleep-wake regulation. Prog. Neurobiol. 73, 379-396.

Bazil, C. W. (2003). Epilepsy and sleep disturbance. Epilepsy Behav. 4(Suppl. 2), S39-S45.

Bennett, D. R. (1963). Sleep deprivation and major motor convulsions. Neurology 13, 953-958. doi: 10.1212/wnl.13.11.953

Berger, A. A., Winnick, A., Welschmeyer, A., Kaneb, A., Berardino, K., Cornett, E. M., et al. (2020). Istradefylline to treat patients with Parkinson's disease experiencing "Off" episodes: a comprehensive review. Neurol. Int. 12, 109-129. doi: $10.3390 /$ neurolint 12030017 avert epilepsy, and thereby prevent the primary antecedent to seizure-induced death.

\section{AUTHOR CONTRIBUTIONS}

All authors listed have made a substantial, direct and intellectual contribution to the work, and approved it for publication.

\section{FUNDING}

DB gratefully acknowledges research funding support provided by the NIH (NS065957 and NS103740) and Citizens United for Research in Epilepsy (DB, CURE Catalyst Award).

Berman, R. F., Fredholm, B. B., Aden, U., and O’Connor, W. T. (2000). Evidence for increased dorsal hippocampal adenosine release and metabolism during pharmacologically induced seizures in rats. Brain Res. 872, 44-53. doi: 10.1016/ s0006-8993(00)02441-0

Bjorklund, O., Shang, M., Tonazzini, I., Dare, E., and Fredholm, B. B. (2008). Adenosine A1 and A3 receptors protect astrocytes from hypoxic damage. Eur. J. Pharmacol. 596, 6-13. doi: 10.1016/j.ejphar.2008.0 8.002

Bjorness, T. E., and Greene, R. W. (2009). Adenosine and sleep. Curr. Neuropharmacol. 7, 238-245.

Boison, D. (2008). Adenosine as a neuromodulator in neurological diseases. Curr. Opin. Pharmacol. 8, 2-7. doi: 10.1016/j.coph.2007.09.002

Boison, D. (2009). Adenosine augmentation therapies (AATs) for epilepsy: prospect of cell and gene therapies. Epilepsy Res. 85, 131-141. doi: 10.1016/j. eplepsyres.2009.03.019

Boison, D. (2012). Adenosine dysfunction in epilepsy. Glia 60, 1234-1243. doi: 10.1002/glia.22285

Boison, D. (2016). Adenosinergic signaling in epilepsy. Neuropharmacology 104, 131-139. doi: 10.1016/j.neuropharm.2015.08.046

Boison, D., and Aronica, E. (2015). Comorbidities in Neurology: is adenosine the common link? Neuropharmacology 97, 18-34. doi: 10.1016/j.neuropharm.2015. 04.031

Boison, D., Singer, P., Shen, H. Y., Feldon, J., and Yee, B. K. (2012). Adenosine hypothesis of schizophrenia-opportunities for pharmacotherapy. Neuropharmacology 62, 1527-1543. doi: 10.1016/j.neuropharm.2011.01.048

Bozymski, K. M., Potter, T. G., Venkatachalam, V., Pandurangi, A. K., and Crouse, E. L. (2018). Caffeine sodium benzoate for electroconvulsive therapy augmentation. J. ECT 34, 233-239. doi: 10.1097/yct.0000000000000503

Brager, D. H., and Thompson, S. M. (2003). Activity-dependent release of adenosine contributes to short-term depression at CA3-CA1 synapses in rat hippocampus. J. Neurophysiol. 89, 22-26. doi: 10.1152/jn.00554.2002

Budde, R. B., Arafat, M. A., Pederson, D. J., Lovick, T. A., Jefferys, J. G. R., and Irazoqui, P. P. (2018). Acid reflux induced laryngospasm as a potential mechanism of sudden death in epilepsy. Epilepsy Res. 148, 23-31. doi: 10.1016/ j.eplepsyres.2018.10.003

Burke, S. P., and Nadler, J. V. (1988). Regulation of glutamate and aspartate release from slices of the hippocampal CA1 area: effects of adenosine and baclofen. J. Neurochem. 51, 1541-1551. doi: 10.1111/j.1471-4159.1988.tb 01123.x

Canals, S., Larrosa, B., Pintor, J., Mena, M. A., and Herreras, O. (2008). Metabolic challenge to glia activates an adenosine-mediated safety mechanism that promotes neuronal survival by delaying the onset of spreading depression waves. J. Cereb. Blood Flow Metab. 28, 1835-1844. doi: 10.1038/jcbfm. 2008.71

Chen, J. F., and Cunha, R. A. (2020). The belated US FDA approval of the adenosine A2A receptor antagonist istradefylline for treatment of Parkinson's disease. Purinergic Signal. 16, 167-174. doi: 10.1007/s11302-020-09694-2 
Chen, J.-F., Huang, Z., Ma, J., Zhu, J., Moratalla, R., Standaert, D., et al. (1999). A2AAdenosine receptor deficiency attenuates brain injury induced by transient focal ischemia in mice. J. Neurosci. 19, 9192-9200. doi: 10.1523/jneurosci.1921-09192.1999

Corvol, J. C., Studler, J. M., Schonn, J. S., Girault, J. A., and Herve, D. (2001). Galpha(olf) is necessary for coupling D1 and A2a receptors to adenylyl cyclase in the striatum. J. Neurochem. 76, 1585-1588. doi: 10.1046/j.1471-4159.2001. 00201.x

Cunha, R. A., Vizi, E. S., Ribeiro, J. A., and Sebastiao, A. M. (1996). Preferential release of ATP and its extracellular catabolism as a source of adenosine upon high- but not low-frequency stimulation of rat hippocampal slices. J. Neurochem. 67, 2180-2187. doi: 10.1046/j.1471-4159.1996.670 52180.x

Daval, J. L., and Nicolas, F. (1994). Opposite effects of cyclohexyladenosine and theophylline on hypoxic damage in cultured neurons. Neurosci. Lett. 175, 114-116. doi: 10.1016/0304-3940(94)91092-8

De Sarro, G., De Sarro, A., Di Paola, E. D., and Bertorelli, R. (1999). Effects of adenosine receptor agonists and antagonists on audiogenic seizure-sensible DBA/2 mice. Eur. J. Pharmacol. 371, 137-145. doi: 10.1016/s0014-2999(99) 00132-6

DeLeo, J., Schubert, P., and Kreutzberg, G. W. (1988). Protection against ischemic brain damage using propentofylline in gerbils. Stroke 19, 1535-1539. doi: 10.1161/01.str.19.12.1535

Devinsky, O., Hesdorffer, D. C., Thurman, D. J., Lhatoo, S., and Richerson, G. (2016). Sudden unexpected death in epilepsy: epidemiology, mechanisms, and prevention. Lancet Neurol. 15, 1075-1088. doi: 10.1016/s1474-4422(16)301582

Di Iorio, P., Battaglia, G., Ciccarelli, R., Ballerini, P., Giuliani, P., Poli, A., et al. (1996). Interaction between Al adenosine and class II metabotropic glutamate receptors in the regulation of purine and glutamate release from rat hippocampal slices. J. Neurochem. 67, 302-309. doi: 10.1046/j.1471-4159.1996. 67010302.x

Dlouhy, B. J., Gehlbach, B. K., and Richerson, G. B. (2016). Sudden unexpected death in epilepsy: basic mechanisms and clinical implications for prevention. J. Neurol. Neurosurg. Psychiatry 87, 402-413. doi: 10.1136/jnnp-2013-307442

Douglas, N. J., White, D. P., Weil, J. V., Pickett, C. K., and Zwillich, C. W. (1982). Hypercapnic ventilatory response in sleeping adults. Am. Rev. Respir. Dis. 126, 758-762.

Dragunow, M., and Goddard, G. V. (1984). Adenosine modulation of amygdala kindling. Exp. Neurol. 84, 654-665. doi: 10.1016/0014-4886(84)90212-7

Dragunow, M., Goddard, G. V., and Laverty, R. (1985). Is adenosine an endogenous anticonvulsant? Epilepsia 26, 480-487. doi: 10.1111/j.1528-1157.1985.tb05684.

Drake, C., Roehrs, T., Shambroom, J., and Roth, T. (2013). Caffeine effects on sleep taken 0, 3, or 6 hours before going to bed. J. Clin. Sleep Med. 9, 1195-1200. doi: $10.5664 /$ jcsm. 3170

Dravet, C. (1978). Les e' pilepsies graves de l'enfant. Vie Med. 59, 543-548.

Dunwiddie, T. V. (1980). "Endogenously released adenosine regulates excitability in the in vitro hippocampus”. Epilepsia 21, 541-548. doi: 10.1111/j.1528-1157. 1980.tb04305.x

Dunwiddie, T. V., and Masino, S. A. (2001). The role and regulation of adenosine in the central nervous system. Annu. Rev. Neurosci. 24, 31-55. doi: 10.1146/ annurev.neuro.24.1.31

During, M. J., and Spencer, D. D. (1992). Adenosine: a potential mediator of seizure arrest and postictal refractoriness. Ann. Neurol. 32, 618-624. doi: 10.1002/ana. 410320504

Dux, E., Schubert, P., and Kreutzberg, G. W. (1992). Ultrastructural localization of calcium in ischemic hippocampal slices: the influence of adenosine and theophylline. J. Cereb. Blood Flow Metab. 12, 520-524. doi: 10.1038/jcbfm.1 992.71

El Yacoubi, M., Ledent, C., Parmentier, M., Costentin, J., and Vaugeois, J.-M. (2008). Evidence for the involvement of the adenosine A2A receptor in the lowered susceptibility to pentylenetetrazol-induced seizures produced in mice by long-term treatment with caffeine. Neuropharmacology 55, 35-40. doi: 10 . 1016/j.neuropharm.2008.04.007

Eldridge, F. L., Millhorn, D. E., and Kiley, J. P. (1984). Respiratory effects of a long-acting analog of adenosine. Brain Res. 301, 273-280. doi: 10.1016/00068993(84)91096-5
Eldridge, F. L., Millhorn, D. E., and Kiley, J. P. (1985). Antagonism by theophylline of respiratory inhibition induced by adenosine. J. Appl. Physiol. (1985) 59, 1428-1433. doi: 10.1152/jappl.1985.59.5.1428

Etherington, L. A., Patterson, G. E., Meechan, L., Boison, D., Irving, A. J., Dale, N., et al. (2009). Astrocytic adenosine kinase regulates basal synaptic adenosine levels and seizure activity but not activity-dependent adenosine release in the hippocampus. Neuropharmacology 56, 429-437. doi: 10.1016/j.neuropharm. 2008.09.016

Evans, M. C., Swan, J. H., and Meldrum, B. S. (1987). An adenosine analogue, 2-chloroadenosine, protects against long term development of ischaemic cell loss in the rat hippocampus. Neurosci. Lett. 83, 287-292. doi: 10.1016/03043940(87)90101-7

Faingold, C. L. (1988). The genetically epilepsy-prone rat. Gen. Pharmacol. Vasc. Syst. 19, 331-338. doi: 10.1016/0306-3623(88)90025-0

Faingold, C. L., Kommajosyula, S. P., Long, X., Plath, K., and Randall, M. (2014). Serotonin and sudden death: differential effects of serotonergic drugs on seizure-induced respiratory arrest in DBA/1 mice. Epilepsy Behav. 37, 198-203. doi: 10.1016/j.yebeh.2014.06.028

Faingold, C. L., Randall, M., and Kommajosyula, S. P. (2016). Susceptibility to seizure-induced sudden death in DBA/2 mice is altered by adenosine. Epilepsy Res. 124, 49-54. doi: 10.1016/j.eplepsyres.2016.05.007

Faingold, C. L., Randall, M., Mhaskar, Y., and Uteshev, V. V. (2011). Differences in serotonin receptor expression in the brainstem may explain the differential ability of a serotonin agonist to block seizure-induced sudden death in DBA/2 vs. DBA/1 mice. Brain Res. 1418, 104-110. doi: 10.1016/j.brainres.2011.08.043

Falquetto, B., Oliveira, L. M., Takakura, A. C., Mulkey, D. K., and Moreira, T. S. (2018). Inhibition of the hypercapnic ventilatory response by adenosine in the retrotrapezoid nucleus in awake rats. Neuropharmacology 138, 47-56. doi: 10.1016/j.neuropharm.2018.05.029

Farrell, J. S., Colangeli, R., Dudok, B., Wolff, M. D., Nguyen, S. L., Jackson, J., et al. (2020). In vivo assessment of mechanisms underlying the neurovascular basis of postictal amnesia. Sci. Rep. 10:14992.

Farrell, J. S., Colangeli, R., Wolff, M. D., Wall, A. K., Phillips, T. J., George, A., et al. (2017). Postictal hypoperfusion/hypoxia provides the foundation for a unified theory of seizure-induced brain abnormalities and behavioral dysfunction. Epilepsia 58, 1493-1501. doi: 10.1111/epi.13827

Farrell, J. S., Gaxiola-Valdez, I., Wolff, M. D., David, L. S., Dika, H. I., Geeraert, B. L., et al. (2016). Postictal behavioural impairments are due to a severe prolonged hypoperfusion/hypoxia event that is COX-2 dependent. Elife 5:e19352.

Fedele, D. E., Li, T., Lan, J. Q., Fredholm, B. B., and Boison, D. (2006). Adenosine A1 receptors are crucial in keeping an epileptic focus localized. Exp. Neurol. 200, 184-190. doi: 10.1016/j.expneurol.2006.02.133

Feuerstein, T. J., Bar, K. I., and Lucking, C. H. (1988). Activation of A1 adenosine receptors decreases the release of serotonin in the rabbit hippocampus, but not in the caudate nucleus. Naunyn Schmiedebergs Arch. Pharmacol. 338, 664-670. doi: $10.1007 /$ bf00165632

Fredholm, B. B. (1982). Adenosine actions and adenosine receptors after 1 week treatment with caffeine. Acta Physiol. Scand. 115, 283-286. doi: 10.1111/j.17481716.1982.tb07078.x

Fredholm, B. B., Battig, K., Holmen, J., Nehlig, A., and Zvartau, E. E. (1999). Actions of caffeine in the brain with special reference to factors that contribute to its widespread use. Pharmacol. Rev. 51, 83-133.

Fredholm, B. B., Chen, J. F., Cunha, R. A., Svenningsson, P., and Vaugeois, J. M. (2005). Adenosine and brain function. Int. Rev. Neurobiol. 63, 191-270.

Fredholm, B. B., Ijzerman, A. P., Jacobson, K. A., Linden, J., and Müller, C. E. (2011). International Union of basic and clinical pharmacology. LXXXI. nomenclature and classification of adenosine receptors-an update. Pharmacol. Rev. 63, 1-34. doi: 10.1124/pr.110.003285

Fukuda, M., Suzuki, Y., Hino, H., Morimoto, T., and Ishii, E. (2011). Activation of central adenosine $\mathrm{A}(2 \mathrm{~A})$ receptors lowers the seizure threshold of hyperthermia-induced seizure in childhood rats. Seizure 20, 156-159. doi: 10.1016/j.seizure.2010.11.012

Gaitatzis, A., Trimble, M. R., and Sander, J. W. (2004). The psychiatric comorbidity of epilepsy. Acta Neurol. Scand. 110, 207-220.

Gao, Y., and Phillis, J. W. (1994). CGS 15943, An adenosine A2 receptor antagonist, reduces cerebral ischemic injury in the mongolian gerbil. Life Sci. 55, L61-L65.

Genton, P., Velizarova, R., and Dravet, C. (2011). Dravet syndrome: the long-term outcome. Epilepsia 52(Suppl. 2), 44-49. doi: 10.1111/j.1528-1167.2011.03001.x 
Gettys, G. C., Liu, F., Kimlin, E., Baghdoyan, H. A., and Lydic, R. (2013). Adenosine $\mathrm{A}(1)$ receptors in mouse pontine reticular formation depress breathing, increase anesthesia recovery time, and decrease acetylcholine release. Anesthesiology 118, 327-336. doi: 10.1097/aln.0b013e31827d413e

Goldberg, M. P., Monyer, H., Weiss, J. H., and Choi, D. W. (1988). Adenosine reduces cortical neuronal injury induced by oxygen or glucose deprivation in vitro. Neurosci. Lett. 89, 323-327. doi: 10.1016/0304-3940(88)90547-2

Gouder, N., Fritschy, J. M., and Boison, D. (2003). Seizure suppression by adenosine A1 receptor activation in a mouse model of pharmacoresistant epilepsy. Epilepsia 44, 877-885. doi: 10.1046/j.1528-1157.2003.03603.x

Gouder, N., Scheurer, L., Fritschy, J. M., and Boison, D. (2004). Overexpression of adenosine kinase in epileptic hippocampus contributes to epileptogenesis. J. Neurosci. 24, 692-701. doi: 10.1523/jneurosci.4781-03.2004

Guttinger, M., Fedele, D., Koch, P., Padrun, V., Pralong, W. F., Brustle, O., et al. (2005). Suppression of kindled seizures by paracrine adenosine release from stem cell-derived brain implants. Epilepsia 46, 1162-1169. doi: 10.1111/j.15281167.2005.61804.x

Guyenet, P. G., Bayliss, D. A., Stornetta, R. L., Ludwig, M. G., Kumar, N. N., Shi, Y., et al. (2016). Proton detection and breathing regulation by the retrotrapezoid nucleus. J. Physiol. 594, 1529-1551. doi: 10.1113/jp271480

Hargus, N. J., Jennings, C., Perez-Reyes, E., Bertram, E. H., and Patel, M. K. (2012). Enhanced actions of adenosine in medial entorhinal cortex layer II stellate neurons in temporal lobe epilepsy are mediated via A(1)-receptor activation. Epilepsia 53, 168-176. doi: 10.1111/j.1528-1167.2011.03337.x

Harms, H. H., Wardeh, G., and Mulder, A. H. (1978). Adenosine modulates depolarization-induced release of $3 \mathrm{H}$-noradrenaline from slices of rat brain neocortex. Eur. J. Pharmacol. 49, 305-308. doi: 10.1016/0014-2999(78)90107-3

Herlenius, E., Lagercrantz, H., and Yamamoto, Y. (1997). Adenosine modulates inspiratory neurons and the respiratory pattern in the brainstem of neonatal rats. Pediatr. Res. 42, 46-53. doi: 10.1203/00006450-199707000-00008

Hesdorffer, T., Tomson, E., Benn, J. W., Sander, L., Nilsson, Y., Langan, T. S., et al. (2011). Combined analysis of risk factors for SUDEP. Epilepsia 52, 1150-1159. doi: 10.1111/j.1528-1167.2010.02952.x

Hodges, M. R., Martino, P., Davis, S., Opansky, C., Pan, L. G., and Forster, H. V. (2004). Effects on breathing of focal acidosis at multiple medullary raphe sites in awake goats. J. Appl. Physiol. (1985) 97, 2303-2309. doi: 10.1152/japplphysiol. 00645.2004

Hodges, M. R., Tattersall, G. J., Harris, M. B., McEvoy, S. D., Richerson, D. N., Deneris, E. S., et al. (2008). Defects in breathing and thermoregulation in mice with near-complete absence of central serotonin neurons. J. Neurosci. 28, 2495-2505. doi: 10.1523/jneurosci.4729-07.2008

Hong, Z.-Y., Huang, Z.-L., Qu, W.-M., Eguchi, N., Urade, Y., and Hayaishi, O. (2005). An adenosine A2A receptor agonist induces sleep by increasing GABA release in the tuberomammillary nucleus to inhibit histaminergic systems in rats. J. Neurochem. 92, 1542-1549. doi: 10.1111/j.1471-4159.2004.02991.x

Hosseinmardi, N., Mirnajafi-Zadeh, J., Fathollahi, Y., and Shahabi, P. (2007). The role of adenosine A1 and A2A receptors of entorhinal cortex on piriform cortex kindled seizures in rats. Pharmacol. Res. 56, 110-117. doi: 10.1016/j.phrs.2007. 04.011

Huber, A., Güttinger, M., Möhler, H., and Boison, D. (2002). Seizure suppression by adenosine A2A receptor activation in a rat model of audiogenic brainstem epilepsy. Neurosci. Lett. 329, 289-292. doi: 10.1016/s0304-3940(02)00684-5

Irizarry, R., Sukato, D., Kollmar, R., Schild, S., Silverman, J., Sundaram, K., et al. (2020). Seizures induce obstructive apnea in DBA/2J audiogenic seizure-prone mice: lifesaving impact of tracheal implants. Epilepsia 61, e13-e16.

Ito, S., Ogiwara, I., Yamada, K., Miyamoto, H., Hensch, T. K., Osawa, M., et al. (2013). Mouse with Nav1.1 haploinsufficiency, a model for Dravet syndrome, exhibits lowered sociability and learning impairment. Neurobiol. Dis. 49, 29-40. doi: $10.1016 /$ j.nbd.2012.08.003

James, S. D., Hawkins, V. E., Falquetto, B., Ruskin, D. N., Masino, S. A., Moreira, T. S., et al. (2018). Adenosine signaling through al receptors inhibits chemosensitive neurons in the retrotrapezoid nucleus. eNeuro 5:ENEURO.0404-18.2018. doi: 10.1523/ENEURO.0404-18.2018

Jehi, L., and Najm, I. M. (2008). Sudden unexpected death in epilepsy: impact, mechanisms, and prevention. Cleve Clin. J. Med. 75(Suppl. 2), S66-S70.

Jeong, H.-J., Jang, I.-S., Nabekura, J., and Akaike, N. (2003). Adenosine A1 receptor-mediated presynaptic inhibition of GABAergic transmission in immature rat hippocampal CA1 neurons. J. Neurophysiol. 89, 1214-1222. doi: 10.1152/jn.00516.2002

Jiang, N., Kowaluk, E. A., Lee, C.-H., Mazdiyasni, H., and Chopp, M. (1997). Adenosine kinase inhibition protects brain against transient focal ischemia in rats. Eur. J. Pharmacol. 320, 131-137. doi: 10.1016/s0014-2999(96)00905-3

Jobe, P. C., Mishra, P. K., dams-Curtis, L. E. A., Deoskar, V. U., Ko, K. H., Browning, R. A., et al. (1995). The genetically epilepsy-prone rat (GEPR). Ital. J. Neurol. Sci. 16, 91-99.

Johansson, B., Halldner, L., Dunwiddie, T. V., Masino, S. A., Poelchen, W., Gimenez-Llort, L., et al. (2001). Hyperalgesia, anxiety, and decreased hypoxic neuroprotection in mice lacking the adenosine A1 receptor. Proc. Natl. Acad. Sci. U.S.A. 98, 9407-9412. doi: 10.1073/pnas.161292398

Kaku, T., Hada, J., and Hayashi, Y. (1994). Endogenous adenosine exerts inhibitory effects upon the development of spreading depression and glutamate release induced by microdialysis with High $\mathrm{K}+$ in rat hippocampus. Brain Res. 658, 39-48. doi: 10.1016/s0006-8993(09)90008-7

Kalume, F., Westenbroek, R. E., Cheah, C. S., Yu, F. H., Oakley, J. C., Scheuer, T., et al. (2013). Sudden unexpected death in a mouse model of Dravet syndrome. J. Clin. Invest. 123, 1798-1808. doi: 10.1172/jci66220

Kim, Y., Bravo, E., Thirnbeck, C. K., Smith-Mellecker, L. A., Kim, S. H., Gehlbach, B. K., et al. (2018). Severe peri-ictal respiratory dysfunction is common in Dravet syndrome. J. Clin. Invest. 128, 1141-1153. doi: 10.1172/jci94999

Kochanek, P. M., Vagni, V. A., Janesko, K. L., Washington, C. B., Crumrine, P. K., Garman, R. H., et al. (2006). Adenosine A1 receptor knockout mice develop lethal status epilepticus after experimental traumatic brain injury. J. Cereb. Blood Flow Metab. 26, 565-575. doi: 10.1038/sj.jcbfm.9600218

Kommajosyula, S. P., Randall, M. E., and Faingold, C. L. (2016). Inhibition of adenosine metabolism induces changes in post-ictal depression, respiration, and mortality in genetically epilepsy prone rats. Epilepsy Res. 119, 13-19. doi: 10.1016/j.eplepsyres.2015.11.001

Koos, B. J., Maeda, T., and Jan, C. (2001). Adenosine A(1) and A(2A) receptors modulate sleep state and breathing in fetal sheep. J. Appl. Physiol. (1985) 91, 343-350. doi: 10.1152/jappl.2001.91.1.343

Kostopoulos, G., Drapeau, C., Avoli, M., Olivier, A., and Villemeure, J. G. (1989). Endogenous adenosine can reduce epileptiform activity in the human epileptogenic cortex maintained in vitro. Neurosci. Lett. 106, 119-124. doi: 10.1016/0304-3940(89)90212-7

Kotagal, P., and Yardi, N. (2008). The relationship between sleep and epilepsy. Semin. Pediatr. Neurol. 15, 42-49.

Kramer, D. R., Fujii, T., Ohiorhenuan, I., and Liu, C. Y. (2017). Interplay between cortical spreading depolarization and seizures. Stereotact. Funct. Neurosurg. 95, 1-5. doi: 10.1159/000452841

Kruse, S. W., Dayton, K. G., Purnell, B. S., Rosner, J. I., and Buchanan, G. F. (2019). Effect of monoamine reuptake inhibition and alphal blockade on respiratory arrest and death following electroshock-induced seizures in mice. Epilepsia 60, 495-507.

Kuo, J., Zhao, W., Li, C. S., Kennedy, J. D., and Seyal, M. (2016). Postictal immobility and generalized EEG suppression are associated with the severity of respiratory dysfunction. Epilepsia 57, 412-417. doi: 10.1111/epi.13312

Lacuey, N., Zonjy, B., Hampson, J. P., Rani, M. R. S., Zaremba, A., Sainju, R. K., et al. (2018). The incidence and significance of periictal apnea in epileptic seizures. Epilepsia 59, 573-582. doi: 10.1111/epi.14006

LaFrance, W. C. Jr., Kanner, A. M., and Hermann, B. (2008). Psychiatric comorbidities in epilepsy. Int. Rev. Neurobiol. 83, 347-383.

Lagercrantz, H., Yamamoto, Y., Fredholm, B. B., Prabhakar, N. R., and von Euler, C. (1984). Adenosine analogues depress ventilation in rabbit neonates. Theophylline stimulation of respiration via adenosine receptors? Pediatr. Res. 18, 387-390. doi: 10.1203/00006450-198404000-00018

Lamberts, R. J., Thijs, R. D., Laffan, A., Langan, Y., and Sander, J. W. (2012). Sudden unexpected death in epilepsy: people with nocturnal seizures may be at highest risk. Epilepsia 53, 253-257. doi: 10.1111/j.1528-1167.2011. 03360.x

Lanigar, S., and Bandyopadhyay, S. (2017). Sleep and epilepsy: a complex interplay. Mo. Med. 114, 453-457.

Larsen, A. K., and Osborne, N. N. (1996). Involvement of adenosine in retinal ischemia. Studies on the rat. Invest. Ophthalmol. Vis. Sci. 37, 2603-2611. 
Latini, S., and Pedata, F. (2001). Adenosine in the central nervous system: release mechanisms and extracellular concentrations. J. Neurochem. 79, 463-484. doi: 10.1046/j.1471-4159.2001.00607.x

Lauritzen, M. (1994). Pathophysiology of the migraine aura: the spreading depression theory. Brain 117, 199-210. doi: 10.1093/brain/117.1.199

Lauritzen, M., Dreier, J. P., Fabricius, M., Hartings, J. A., Graf, R., and Strong, A. J. (2011). Clinical relevance of cortical spreading depression in neurological disorders: migraine, malignant stroke, subarachnoid and intracranial hemorrhage, and traumatic brain injury. J. Cereb. Blood Flow Metab. 31, 17-35. doi: 10.1038/jcbfm.2010.191

Lawson, E. E., and Long, W. A. (1983). Central origin of biphasic breathing pattern during hypoxia in newborns. J. Appl. Physiol. Respir. Environ. Exerc. Physiol. 55, 483-488. doi: 10.1152/jappl.1983.55.2.483

Leal-Campanario, R., Alarcon-Martinez, L., Rieiro, H., Martinez-Conde, S., Alarcon-Martinez, T., Zhao, X., et al. (2017). Abnormal capillary vasodynamics contribute to ictal neurodegeneration in epilepsy. Sci. Rep. 7:43276.

Leo, A. A. P. (1944). Spreading depression of activity in the cerebral cortex. J. Neurophysiol. 7, 359-390. doi: 10.1152/jn.1944.7.6.359

Lhatoo, S. D., Faulkner, H. J., Dembny, K., Trippick, K., Johnson, C., and Bird, J. M. (2010). An electroclinical case-control study of sudden unexpected death in epilepsy. Ann. Neurol. 68, 787-796. doi: 10.1002/ana.22101

Li, T. F., Ren, G. Y., Lusardi, T., Wilz, A., Lan, J. Q., Iwasato, T., et al. (2008). Adenosine kinase is a target for the prediction and prevention of epileptogenesis in mice. J. Clin. Invest. 118, 571-582.

Lin, Y., and Phillis, J. W. (1992). Deoxycoformycin and oxypurinol: protection against focal ischemic brain injury in the rat. Brain Res. 571, 272-280. doi: 10.1016/0006-8993(92)90665-v

Lindquist, B. E., and Shuttleworth, C. W. (2012). Adenosine receptor activation is responsible for prolonged depression of synaptic transmission after spreading depolarization in brain slices. Neuroscience 223, 365-376. doi: 10.1016/j. neuroscience.2012.07.053

Lindquist, B. E., and Shuttleworth, C. W. (2014). Spreading depolarization-induced adenosine accumulation reflects metabolic status in vitro and in vivo. J. Cereb. Blood Flow Metab. 34, 1779-1790. doi: 10.1038/jcbfm.2014.146

Lindquist, B. E., and Shuttleworth, C. W. (2017). Evidence that adenosine contributes to Leao's spreading depression in vivo. J. Cereb. Blood Flow Metab. 37, 1656-1669. doi: 10.1177/0271678x16650696

Lloyd, H. G. E., Lindström, K., and Fredholm, B. B. (1993). Intracellular formation and release of adenosine from rat hippocampal slices evoked by electrical stimulation or energy depletion. Neurochem. Int. 23, 173-185. doi: 10.1016/ 0197-0186(93)90095-m

Loonen, I. C. M., Jansen, N. A., Cain, S. M., Schenke, M., Voskuyl, R. A., Yung, A. C., et al. (2019). Brainstem spreading depolarization and cortical dynamics during fatal seizures in Cacnala S218L mice. Brain 142, 412-425. doi: 10.1093/ brain/awy325

Lopes, J. M., Davis, G. M., Mullahoo, K., and Aranda, J. V. (1994). Role of adenosine in the hypoxic ventilatory response of the newborn piglet. Pediatr. Pulmonol. 17, 50-55. doi: 10.1002/ppul.1950170109

Lopes, L. V., Cunha, R. A., Kull, B., Fredholm, B. B., and Ribeiro, J. A. (2002). Adenosine A2A receptor facilitation of hippocampal synaptic transmission is dependent on tonic A1 receptor inhibition. Neuroscience 112, 319-329. doi: 10.1016/s0306-4522(02)00080-5

Lovatt, D., Xu, Q., Liu, W., Takano, T., Smith, N. A., Schnermann, J., et al. (2012). Neuronal adenosine release, and not astrocytic ATP release, mediates feedback inhibition of excitatory activity. Proc. Natl. Acad. Sci. U.S.A. 109, 6265-6270. doi: 10.1073/pnas.1120997109

Lusardi, T. A., Akula, K. K., Coffman, S. Q., Ruskin, D. N., Masino, S. A., and Boison, D. (2015). Ketogenic diet prevents epileptogenesis and disease progression in adult mice and rats. Neuropharmacology 99, 500-509. doi: 10.1016/j.neuropharm.2015.08.007

Lynch, J. J. III, Alexander, K. M., Jarvis, M. F., and Kowaluk, E. A. (1998). Inhibition of adenosine kinase during oxygen-glucose deprivation in rat cortical neuronal cultures. Neurosci. Lett. 252, 207-210. doi: 10.1016/s0304-3940(98)00376-0

MacDonald, R. L., Skerritt, J. H., and Werz, M. A. (1986). Adenosine agonists reduce voltage-dependent calcium conductance of mouse sensory neurones in cell culture. J. Physiol. 370, 75-90. doi: 10.1113/jphysiol.1986.sp015923
Massey, C. A., Sowers, L. P., Dlouhy, B. J., and Richerson, G. B. (2014). Mechanisms of sudden unexpected death in epilepsy: the pathway to prevention. Nat. Rev. Neurol. 10, 271-282. doi: 10.1038/nrneurol.2014.64

Matsumoto, K., Sakaki, T., Kohmura, E., Hayakawa, T., and Yamada, K. (1996). Amelioration of ischemic brain damage by the preischemic administration of propentofylline (HWA285) in a rat focal ischemia. Brain Res. 723, 228-230. doi: 10.1016/0006-8993(96)00258-2

Mayer, C. A., Haxhiu, M. A., Martin, R. J., and Wilson, C. G. (2006). Adenosine A2A receptors mediate GABAergic inhibition of respiration in immature rats. J. Appl. Physiol. (1985) 100, 91-97. doi: 10.1152/japplphysiol.00459.2005

Medic, G., Wille, M., and Hemels, M. E. (2017). Short- and long-term health consequences of sleep disruption. Nat. Sci. Sleep 9, 151-161. doi: 10.2147/nss. s134864

Mendez, M., and Radtke, R. A. (2001). Interactions between sleep and epilepsy. J. Clin. Neurophysiol. 18, 106-127. doi: 10.1097/00004691-200103000-0 0003

Merricks, E. M., Smith, E. H., McKhann, G. M., Goodman, R. R., Bateman, L. M., Emerson, R. G., et al. (2015). Single unit action potentials in humans and the effect of seizure activity. Brain 138(Pt 10), 2891-2906. doi: 10.1093/brain/ awv208

Miller, L. P., Jelovich, L. A., Yao, L., DaRe, J., Ugarkar, B., and Foster, A. C. (1996). Pre-and peristroke treatment with the adenosine kinase inhibitor, 5 -deoxyiodotubercidin, significantly reduces infarct volume after temporary occlusion of the middle cerebral artery in rats. Neurosci. Lett. 220, 73-76. doi: 10.1016/s0304-3940(96)13234- 1

Mitchell, J. B., Lupica, C. R., and Dunwiddie, T. V. (1993). Activity-dependent release of endogenous adenosine modulates synaptic responses in the rat hippocampus. J. Neurosci. 13, 3439-3447. doi: 10.1523/jneurosci.13-08-03439. 1993

Moore, B. M., Jerry Jou, C., Tatalovic, M., Kaufman, E. S., Kline, D. D., and Kunze, D. L. (2014). The Kv1.1 null mouse, a model of sudden unexpected death in epilepsy (SUDEP). Epilepsia 55, 1808-1816. doi: 10.1111/epi.12793

Mori, M., Nishizaki, T., and Okada, Y. (1992). Protective effect of adenosine on the anoxic damage of hippocampal slice. Neuroscience 46, 301-307. doi: 10.1016/ 0306-4522(92)90052-4

Morii, S., Ngai, A. C., and Winn, H. R. (1986). Reactivity of rat pial arterioles and venules to adenosine and carbon dioxide: with detailed description of the closed cranial window technique in rats. J. Cereb. Blood Flow Metab. 6, 34-41. doi: $10.1038 /$ jcbfm. 1986.5

Motelow, J. E., Li, W., Zhan, Q., Mishra, A. M., Sachdev, R. N., Liu, G., et al. (2015). Decreased subcortical cholinergic arousal in focal seizures. Neuron $85,561-572$. doi: 10.1016/j.neuron.2014.12.058

Murray, T. F., Sylvester, D., Schultz, C. S., and Szot, P. (1985). Purinergic modulation of the seizure threshold for pentylenetetrazol in the rat. Neuropharmacology 24, 761-766. doi: 10.1016/0028-3908(85)90010-3

Nakase, K., Kollmar, R., Lazar, J., Arjomandi, H., Sundaram, K., Silverman, J., et al. (2016). Laryngospasm, central and obstructive apnea during seizures: defining pathophysiology for sudden death in a rat model. Epilepsy Res. 128, 126-139. doi: 10.1016/j.eplepsyres.2016.08.004

Newton, M. R., Berkovic, S. F., Austin, M. C., Rowe, C. C., McKay, W. J., and Bladin, P. F. (1992). Postictal switch in blood flow distribution and temporal lobe seizures. J. Neurol. Neurosurg. Psychiatry 55, 891-894. doi: 10.1136/jnnp. 55.10 .891

Nguyen, M. D., and Venton, B. J. (2015). Fast-scan cyclic voltammetry for the characterization of rapid adenosine release. Comput. Struct. Biotechnol. J. 13, 47-54. doi: 10.1016/j.csbj.2014.12.006

Okada, M., Nutt, D. J., Murakami, T., Zhu, G., Kamata, A., Kawata, Y., et al. (2001). Adenosine receptor subtypes modulate two major functional pathways for hippocampal serotonin release. J. Neurosci. 21, 628-640. doi: 10.1523/ jneurosci.21-02-00628.2001

Pajski, M. L., and Venton, B. J. (2010). Adenosine release evoked by short electrical stimulations in striatal brain slices is primarily activity dependent. ACS Chem. Neurosci. 1, 775-787. doi: 10.1021/cn100037d

Pajski, M. L., and Venton, B. J. (2013). The mechanism of electrically stimulated adenosine release varies by brain region. Purinergic Signal. 9, 167-174. doi: 10.1007/s11302-012-9343-2 
Palchykova, S., Winsky-Sommerer, R., Shen, H. Y., Boison, D., Gerling, A., and Tobler, I. (2010). Manipulation of adenosine kinase affects sleep regulation in mice. J. Neurosci. 30, 13157-13165. doi: 10.1523/jneurosci.1359-10.2010

Pascual, O., Casper, K. B., Kubera, C., Zhang, J., Revilla-Sanchez, R., Sul, J. Y., et al. (2005). Astrocytic purinergic signaling coordinates synaptic networks. Science 310, 113-116. doi: 10.1126/science.1116916

Patodia, S., Paradiso, B., Garcia, M., Ellis, M., Diehl, B., Thom, M., et al. (2020). Adenosine kinase and adenosine receptors A1 R and A2A R in temporal lobe epilepsy and hippocampal sclerosis and association with risk factors for SUDEP. Epilepsia 61, 787-797. doi: 10.1111/epi.16487

Peng, W., Wu, Z., Song, K., Zhang, S., Li, Y., and Xu, M. (2020). Regulation of sleep homeostasis mediator adenosine by basal forebrain glutamatergic neurons. Science 369:eabb0556. doi: 10.1126/science.abb0556

Petrucci, A. N., Joyal, K. G., Purnell, B. S., and Buchanan, G. F. (2019). Serotonin and sudden unexpected death in epilepsy. Exp. Neurol. 325:113145.

Petrucci, A. N., Joyal, K. G., Purnell, B. S., and Buchanan, G. F. (2020). Serotonin and sudden unexpected death in epilepsy. Exp. Neurol. 325:113145.

Phillips, T. J., Gom, R. C., Wolff, M. D., and Teskey, G. C. (2019). Caffeine exacerbates postictal hypoxia. Neuroscience 422, 32-43. doi: 10.1016/j. neuroscience.2019.09.025

Phillis, J. W. (1995). The effects of selective A1 and A2a adenosine receptor antagonists on cerebral ischemic injury in the gerbil. Brain Res. 705, 79-84. doi: 10.1016/0006-8993(95)01153-6

Phillis, J. W., and O’Regan, M. H. (1989). Deoxycoformycin antagonizes ischemiainduced neuronal degeneration. Brain Res. Bull. 22, 537-540. doi: 10.1016/ 0361-9230(89)90107-x

Pianosi, P., Grondin, D., Desmond, K., Coates, A. L., and Aranda, J. V. (1994). Effect of caffeine on the ventilatory response to inhaled carbon dioxide. Respir. Physiol. 95, 311-320. doi: 10.1016/0034-5687(94)90093-0

Pietrobon, D., and Moskowitz, M. A. (2014). Chaos and commotion in the wake of cortical spreading depression and spreading depolarizations. Nat. Rev. Neurosci. 15, 379-393. doi: 10.1038/nrn3770

Popoli, P., Betto, P., Reggio, R., and Ricciarello, G. (1995). Adenosine A2A receptor stimulation enhances striatal extracellular glutamate levels in rats. Eur. J. Pharmacol. 287, 215-217. doi: 10.1016/0014-2999(95)00679-6

Popoli, P., Frank, C., Tebano, M. T., Potenza, R. L., Pintor, A., Domenici, M. R., et al. (2003). Modulation of glutamate release and excitotoxicity by adenosine A2A receptors. Neurology 61(11 Suppl. 6), S69-S71.

Porkka-Heiskanen, T., Strecker, R. E., and McCarley, R. W. (2000). Brain site-specificity of extracellular adenosine concentration changes during sleep deprivation and spontaneous sleep: an in vivo microdialysis study. Neuroscience 99, 507-517. doi: 10.1016/s0306-4522(00)00220-7

Porkka-Heiskanen, T., Strecker, R. E., Thakkar, M., Bjorkum, A. A., Greene, R. W., and McCarley, R. W. (1997). Adenosine: a mediator of the sleep-inducing effects of prolonged wakefulness. Science 276, 1265-1268. doi: 10.1126/science.276. 5316.1265

Posner, J. B., Plum, F., and Van Poznak, A. (1969). Cerebral metabolism during electrically induced seizures in man. Arch. Neurol. 20, 388-395. doi: 10.1001/ archneur.1969.00480100064010

Purnell, B. S., Thijs, R. D., and Buchanan, G. F. (2018). Dead in the night: sleepwake and time-of-day influences on sudden unexpected death in epilepsy. Front. Neurol. 9:1079. doi: 10.3389/fneur.2018.01079

Quarta, D., Ferre, S., Solinas, M., You, Z. B., Hockemeyer, J., Popoli, P., et al. (2004). Opposite modulatory roles for adenosine $\mathrm{A} 1$ and $\mathrm{A} 2 \mathrm{~A}$ receptors on glutamate and dopamine release in the shell of the nucleus accumbens. Effects of chronic caffeine exposure. J. Neurochem. 88, 1151-1158. doi: 10.1046/j.1471-4159.2003. 02245.x

Rainnie, D. G., Grunze, H. C., McCarley, R. W., and Greene, R. W. (1994). Adenosine inhibition of mesopontine cholinergic neurons: implications for EEG arousal. Science 263, 689-692. doi: 10.1126/science.8303279

Rezvani, M. E., Mirnajafi-Zadeh, J., Fathollahi, Y., and Palizvan, M. R. (2007). Anticonvulsant effect of A1 but not A2A adenosine receptors of piriform cortex in amygdala-kindled rats. Can. J. Physiol. Pharmacol. 85, 606-612. doi: 10.1139/y07-046

Rheims, S., Alvarez, B. M., Alexandre, V., Curot, J., Maillard, L., Bartolomei, F., et al. (2019). Hypoxemia following generalized convulsive seizures: risk factors and effect of oxygen therapy. Neurology 92, e183-e193.
Richerson, G. B., and Buchanan, G. F. (2011). The serotonin axis: shared mechanisms in seizures, depression, and SUDEP. Epilepsia 52(Suppl. 1), 28-38. doi: 10.1111/j.1528-1167.2010.02908.x

Rosen, J. B., and Berman, R. F. (1985). Prolonged postictal depression in amygdalakindled rats by the adenosine analog, l-phenylisopropyladenosine. Exp. Neurol. 90, 549-557. doi: 10.1016/0014-4886(85)90152-9

Rosenquist, P. B., McCall, W. V., Farah, A., and Reboussin, D. M. (1994). Effects of caffeine pretreatment on measures of seizure impact. Convuls. Ther. 10, 181-185.

Ryvlin, P., Nashef, L., Lhatoo, S. D., Bateman, L. M., Bird, J., Bleasel, A., et al. (2013). Incidence and mechanisms of cardiorespiratory arrests in epilepsy monitoring units (MORTEMUS): a retrospective study. Lancet Neurol. 12, 966-977. doi: 10.1016/s1474-4422(13)70214-x

Sandau, U. S., Yahya, M., Bigej, R., Friedman, J. L., Saleumvong, B., and Boison, D. (2019). Transient use of a systemic adenosine kinase inhibitor attenuates epilepsy development in mice. Epilepsia 60, 615-625. doi: 10.1111/epi.14674

Schrader, J., Wahl, M., Kuschinsky, W., and Kreutzberg, G. W. (1980). Increase of adenosine content in cerebral cortex of the cat during bicuculline-induced seizure. Pflugers Arch. 387, 245-251. doi: 10.1007/bf0058 0977

Sciotti, V. M., Park, T. S., Berne, R. M., and Van Wylen, D. G. L. (1993). Changes in extracellular adenosine during chemical or electrical brain stimulation. Brain Res. 613, 16-20. doi: 10.1016/0006-8993(93)90448-v

Seidel, J. L., Escartin, C., Ayata, C., Bonvento, G., and Shuttleworth, C. W. (2016). Multifaceted roles for astrocytes in spreading depolarization: a target for limiting spreading depolarization in acute brain injury? Glia 64, 5-20. doi: 10.1002/glia.22824

Seyal, M., Bateman, L. M., and Li, C. S. (2013). Impact of periictal interventions on respiratory dysfunction, postictal EEG suppression, and postictal immobility. Epilepsia 54, 377-382. doi: 10.1111/j.1528-1167.2012.0 3691.x

Seyal, M., Hardin, K. A., and Bateman, L. M. (2012). Postictal generalized EEG suppression is linked to seizure-associated respiratory dysfunction but not postictal apnea. Epilepsia 53, 825-831. doi: 10.1111/j.1528-1167.2012.03443.x

Shefner, S. A., and Chiu, T. H. (1986). Adenosine inhibits locus coeruleus neurons: an intracellular study in a rat brain slice preparation. Brain Res. 366, 364-368. doi: 10.1016/0006-8993(86)91320-x

Shen, H. Y., Li, T., and Boison, D. (2010). A novel mouse model for sudden unexpected death in epilepsy (SUDEP): role of impaired adenosine clearance. Epilepsia 51, 465-468. doi: 10.1111/j.1528-1167.2009.02248.x

Shen, H. Y., Singer, P., Lytle, N., Wei, C. J., Lan, J. Q., Williams-Karnesky, R. L., et al. (2012). Adenosine augmentation ameliorates psychotic and cognitive endophenotypes of schizophrenia. J. Clin. Invest. 122, 2567-2577. doi: 10.1172/ jci62378

Ssentongo, P., Robuccio, A. E., Thuku, G., Sim, D. G., Nabi, A., Bahari, F., et al. (2017). A murine model to study epilepsy and SUDEP induced by malaria infection. Sci. Rep. 7:43652.

Staniszewska, A., Maka, A., Religioni, U., and Olejniczak, D. (2017). Sleep disturbances among patients with epilepsy. Neuropsychiatr. Dis. Treat. 13, 1797-1803. doi: $10.2147 /$ ndt.s 136868

Steinhoff, B. J., Herrendorf, G., and Kurth, C. (1996). Ictal near infrared spectroscopy in temporal lobe epilepsy: a pilot study. Seizure 5, 97-101. doi: 10.1016/s1059-1311(96)80101-4

Stewart, M., Kollmar, R., Nakase, K., Silverman, J., Sundaram, K., Orman, R., et al. (2017). Obstructive apnea due to laryngospasm links ictal to postictal events in SUDEP cases and offers practical biomarkers for review of past cases and prevention of new ones. Epilepsia 58, e87-e90.

Sulakhe, P. V., and Phillis, J. W. (1975). The release of $3 \mathrm{H}$-adenosine and its derivatives from cat sensorimotor cortex. Life Sci. 17, 551-555. doi: 10.1016/ 0024-3205(75)90089-2

Tao, J. X., Qian, S., Baldwin, M., Chen, X. J., Rose, S., Ebersole, S. H., et al. (2010). SUDEP, suspected positional airway obstruction, and hypoventilation in postictal coma. Epilepsia 51, 2344-2347. doi: 10.1111/j.1528-1167.2010.02719.x

Tawfik, V. L., Chang, S. Y., Hitti, F. L., Roberts, D. W., Leiter, J. C., Jovanovic, S., et al. (2010). Deep brain stimulation results in local glutamate and adenosine release: investigation into the role of astrocytes. Neurosurgery 67, 367-375. doi: 10.1227/01.neu.0000371988.73620.4c 
Taylor, D. A., and Stone, T. W. (1980). The action of adenosine on noradrenergic neuronal inhibition induced by stimulation of locus coeruleus. Brain Res. 183, 367-376. doi: 10.1016/0006-8993(80)90471-0

Teran, F. A., Massey, C. A., and Richerson, G. B. (2014). Serotonin neurons and central respiratory chemoreception: where are we now? Prog. Brain Res. 209, 207-233. doi: 10.1016/b978-0-444-63274-6.00011-4

Theeranaew, W., McDonald, J., Zonjy, B., Kaffashi, F., Moseley, B. D., Friedman, D., et al. (2018). Automated detection of postictal generalized EEG suppression. IEEE Trans. Biomed. Eng. 65, 371-377.

Thurman, D. J., Hesdorffer, D. C., and French, J. A. (2014). Sudden unexpected death in epilepsy: assessing the public health burden. Epilepsia 55, 1479-1485. doi: 10.1111/epi.12666

Trussell, L. O., and Jackson, M. B. (1985). Adenosine-activated potassium conductance in cultured striatal neurons. Proc. Natl. Acad. Sci. U.S.A. 82, 4857-4861. doi: 10.1073/pnas.82.14.4857

Tupal, S., and Faingold, C. L. (2006). Evidence supporting a role of serotonin in modulation of sudden death induced by seizures in DBA/2 mice. Epilepsia 47, 21-26. doi: 10.1111/j.1528-1167.2006.00365.x

Uzbay, T. I., Kayir, H., and Ceyhan, M. (2007). Effects of tianeptine on onset time of pentylenetetrazole-induced seizures in mice: possible role of adenosine A1 receptors. Neuropsychopharmacology 32, 412-416. doi: 10.1038/sj.npp.130 1143

Van Gompel, J. J., Bower, M. R., Worrell, G. A., Stead, M., Chang, S. Y., Goerss, S. J., et al. (2014). Increased cortical extracellular adenosine correlates with seizure termination. Epilepsia 55, 233-244. doi: 10.1111/epi.12511

Vega, J. L. (2018). Ictal mammalian dive response: a likely cause of sudden unexpected death in epilepsy. Front. Neurol. 9:677. doi: 10.3389/fneur.2018. 00677

Vilella, L., Lacuey, N., Hampson, J. P., Rani, M. R. S., Loparo, K., Sainju, R. K., et al. (2019). Incidence, recurrence, and risk factors for Peri-ictal central apnea and sudden unexpected death in epilepsy. Front. Neurol. 10:166. doi: 10.3389/fneur. 2019.00166

Vizek, M., Pickett, C. K., and Weil, J. V. (1987). Biphasic ventilatory response of adult cats to sustained hypoxia has central origin. J. Appl. Physiol. (1985) 63, 1658-1664. doi: 10.1152/jappl.1987.63.4.1658

Von Lubitz, D. K. J. E., Lin, R. C. S., and Jacobson, K. A. (1995). Cerebral ischemia in gerbils: effects of acute and chronic treatment with adenosine A2A receptor agonist and antagonist. Eur. J. Pharmacol. 287, 295-302. doi: 10.1016/00142999(95)00498-x

Von Lubitz, D. K. J. E., Lin, R. C. S., Melman, N., Xiao-duo, J., Carter, M. F., and Jacobson, K. A. (1994). Chronic administration of selective adenosine A1 receptor agonist or antagonist in cerebral ischemia. Eur. J. Pharmacol. 256, 161-167. doi: 10.1016/0014-2999(94)90241-0

von Lubitz, D. K., Dambrosia, J. M., Kempski, O., and Redmond, D. J. (1988). Cyclohexyl adenosine protects against neuronal death following ischemia in the CA1 region of gerbil hippocampus. Stroke 19, 1133-1139. doi: 10.1161/01.str. 19.9.1133

Wall, M. J., and Dale, N. (2013). Neuronal transporter and astrocytic ATP exocytosis underlie activity-dependent adenosine release in the hippocampus. J. Physiol. 591, 3853-3871. doi: 10.1113/jphysiol.2013.253450

Wall, M., and Dale, N. (2008). Activity-dependent release of adenosine: a critical re-evaluation of mechanism. Curr. Neuropharmacol. 6, 329-337. doi: 10.2174/ 157015908787386087

Warren, T. J., Simeone, T. A., Smith, D. D., Grove, R., Adamec, J., Samson, K. K., et al. (2018). Adenosine has two faces: regionally dichotomous adenosine tone in a model of epilepsy with comorbid sleep disorders. Neurobiol. Dis. 114, 45-52. doi: 10.1016/j.nbd.2018.01.017
Whitcomb, K., Lupica, C. R., Rosen, J. B., and Berman, R. F. (1990). Adenosine involvement in postictal events in amygdala-kindled rats. Epilepsy Res. 6, 171-179. doi: 10.1016/0920-1211(90)90070-c

Williams-Karnesky, R. L., Sandau, U. S., Lusardi, T. A., Lytle, N. K., Farrell, J. M., Pritchard, E. M., et al. (2013). Epigenetic changes induced by adenosine augmentation therapy prevent epileptogenesis. J. Clin. Invest. 123, 3552-3563. doi: $10.1172 /$ jci65636

Wilson, C. G., Martin, R. J., Jaber, M., Abu-Shaweesh, J., Jafri, A., Haxhiu, M. A., et al. (2004). Adenosine A2A receptors interact with GABAergic pathways to modulate respiration in neonatal piglets. Respir. Physiol. Neurobiol. 141, 201-211. doi: 10.1016/j.resp.2004.04.012

Yan, S., Laferriere, A., Zhang, C., and Moss, I. R. (1995). Microdialyzed adenosine in nucleus tractus solitarii and ventilatory response to hypoxia in piglets. J. Appl. Physiol. (1985) 79, 405-410. doi: 10.1152/jappl.1995.79.2.405

Yee, B. K., Singer, P., Chen, J. F., Feldon, J., and Boison, D. (2007). Transgenic overexpression of adenosine kinase in brain leads to multiple learning impairments and altered sensitivity to psychomimetic drugs. Eur. J. Neurosci. 26, 3237-3252. doi: 10.1111/j.1460-9568.2007.05897.x

Young, D., and Dragunow, M. (1994). Status Epilepticus May Be Caused by Loss of Adenosine Anticonvulsant Mechanisms. Neuroscience 58, 245-261. doi: 10.1016/0306-4522(94)90032-9

Yum, D.-S., Cho, J.-H., Choi, I.-S., Nakamura, M., Lee, J.-J., Lee, M.-G., et al. (2008). Adenosine A1receptors inhibit GABAergic transmission in rat tuberomammillary nucleus neurons. J. Neurochem. 106, 361-371. doi: 10.1111/ j.1471-4159.2008.05400.x

Zeraati, M., Mirnajafi-Zadeh, J., Fathollahi, Y., Namvar, S., and Rezvani, M. E. (2006). Adenosine A1 and A2A receptors of hippocampal CA1 region have opposite effects on piriform cortex kindled seizures in rats. Seizure 15, 41-48. doi: 10.1016/j.seizure.2005.10.006

Zhan, Q., Buchanan, G. F., Motelow, J. E., Andrews, J., Vitkovskiy, P., Chen, W. C., et al. (2016). Impaired serotonergic brainstem function during and after seizures. J. Neurosci. 36, 2711-2722. doi: 10.1523/jneurosci.4331-15. 2016

Zhang, H., Zhao, H., and Feng, H. J. (2017). Atomoxetine, a norepinephrine reuptake inhibitor, reduces seizure-induced respiratory arrest. Epilepsy Behav. 73, 6-9. doi: 10.1016/j.yebeh.2017.04.046

Zhang, H., Zhao, H., Zeng, C., Van Dort, C., Faingold, C. L., Taylor, N. E., et al. (2018). Optogenetic activation of 5-HT neurons in the dorsal raphe suppresses seizure-induced respiratory arrest and produces anticonvulsant effect in the DBA/1 mouse SUDEP model. Neurobiol. Dis. 110, 47-58. doi: 10.1016/j.nbd. 2017.11.003

Zhao, H., Cotten, J. F., Long, X., and Feng, H. J. (2017). The effect of atomoxetine, a selective norepinephrine reuptake inhibitor, on respiratory arrest and cardiorespiratory function in the DBA/1 mouse model of SUDEP. Epilepsy Res. 137, 139-144. doi: 10.1016/j.eplepsyres.2017. 08.005

Conflict of Interest: The authors declare that the research was conducted in the absence of any commercial or financial relationships that could be construed as a potential conflict of interest.

Copyright (c) 2021 Purnell, Murugan, Jani and Boison. This is an open-access article distributed under the terms of the Creative Commons Attribution License (CC BY). The use, distribution or reproduction in other forums is permitted, provided the original author(s) and the copyright owner(s) are credited and that the original publication in this journal is cited, in accordance with accepted academic practice. No use, distribution or reproduction is permitted which does not comply with these terms. 